JENIFFER NOVAES

\title{
Análise da expressão diferencial entre merozoítos e esporozoítos de \\ Eimeria tenella empregando a técnica de LongSAGE
}

Tese apresentada ao Instituto de Ciências Biomédicas da Universidade de São Paulo, para obtenção do Título de Doutor em Ciências.

Área de Concentração: Biologia da Relação Patógeno-Hospedeiro.

Orientadora:

Profa. Dra. Alda Maria Backx N. Madeira

São Paulo 


\section{RESUMO}

Novaes J. Análise da expressão diferencial entre merozoítos e esporozoítos de Eimeria tenella empregando a técnica de LongSAGE [Tese]. São Paulo: Instituto de Ciências Biomédicas da Universidade de São Paulo; 2009.

A coccidiose aviária é causada por protozoários do gênero Eimeria e é responsável por grandes prejuízos à indústria avícola mundial. O nosso grupo gerou e anotou mais de 15.000 seqüências expressas do tipo ORESTES das três principais espécies de Eimeria que acometem a galinha doméstica. Dentre estas, a Eimeria tenella é a mais estudada devido a sua alta freqüência e virulência no campo, sendo empregada como modelo de estudo para coccidiose. Com o objetivo de se estudar o perfil de expressão quantitativo de dois estágios invasivos destes parasitas, foram construídas bibliotecas de LongSAGE a partir de merozoítos de segunda geração e esporozoítos. As seqüências de DNA foram submetidas a um processo seriado de múltiplos passos utilizando a plataforma Egene e, apenas seqüências apresentando alta qualidade foram consideradas para as etapas posteriores. A extração e contagem das tags foram realizadas utilizando o SAGE Analysis, um pacote desenvolvido localmente. Para análise estatística foi empregado o Kemp, uma implementação de um teste freqüentista. No total, obtivemos mais de 35.000 tags, que corresponde a 9.516 tags únicas. Deste conjunto, 270 tags foram classificadas como diferencialmente expressas e utilizadas como sementes para a reconstrução dos cDNAs correspondentes utilizando cerca de 48.000 leituras de ORESTES/ESTs e o programa GenSeed. Um total de 199 seqüências de cDNA foram reconstruídas com sucesso e submetidas a um pipeline de anotação automática empregando o Egene. O processo de anotação consistiu na identificação das seqüências codificadoras, e a caracterização dos produtos correspondentes utilizando buscas de similaridade, buscas de motivos protéicos, detecção de ortólogos e mapeamento de ontologia gênica. Estes resultados mostraram que, apesar de invasivos, estes estágios apresentam genes de expressão estágio-específica e um perfil transcricional distinto. Para merozoítos, grande parte dos produtos protéicos diferencialmente expressos estavam relacionados à tradução, modificação e manutenção da conformação das proteínas e processos de ligação. Enquanto que em esporozoítos, o perfil transcricional obtido foi distinto, com poucos resultados 
positivos de BLAST. Alguns dos produtos protéicos identificados foram as histonas, proteínas associadas a transporte e atividade catalítica. Uma validação experimental preliminar utilizando um pequeno conjunto de genes foi realizada e uma boa correlação entre estas técnicas foi obtida ao se comparar os dados quantitativos de expressão gênica. A análise comparativa entre os dados diferencialmente expressos obtidos por LongSAGE e Northern Digital de ESTs/ORESTES de E. tenella mostrou que há coerência entre os dados obtidos, já que muitos genes diferencialmente expressos foram identificados por ambas as técnicas.

Palavras-chave: Coccidiose. Eimeria tenella. Expressão gênica. Merozoítos. Esporozoítos. Etiquetas de seqüências expressas. 


\begin{abstract}
Novaes J. Differential expression analysis between merozoites and sporozoites of Eimeria tenella using LongSAGE [Thesis]. São Paulo: Instituto de Ciências Biomédicas da Universidade de São Paulo; 2009.
\end{abstract}

Coccidiosis of the domestic fowl is caused by protozoan parasites of the genus Eimeria. The disease is world widely distributed and is responsible for relevant economic losses to the poultry industry. Our group generated and annotated more than 15.000 expressed sequences (ORESTES) for each one of the three most important Eimeria species. Eimeria tenella is the most studied species due to its high prevalence and virulence, and because is more amenable to laboratory manipulation. For these reasons, E. tenella became the model species on coccidiosis research. Aiming at obtaining a quantitative expression profile of two invasive stages of these parasites, we constructed LongSAGE libraries of sporozoites and second-generation merozoites. DNA reads were submitted to a multistep processing pipeline using EGene platform, and only sequence stretches showing high quality were considered for downstream analyses. Tag extraction and counting were performed using SAGE Analysis, a locally developed package. For the statistical analysis we used Kemp, an implementation of a frequentist test. In total we have obtained more than 35,000 tags, which correspond to 9,5126 unique tags. From this set, 270 tags were considered differentially expressed and utilized as seeds to reconstruct the corresponding cDNAs using circa 48,000 ORESTES/EST reads and the program GenSeed. A total of 199 cDNAs sequences were successfully reconstructed and submitted to an automated annotation pipeline using EGene. The annotation process consisted on the identification of the coding sequences, and the characterization of the corresponding products using similarity searches, protein motif finding, orthology detection and gene ontology mapping. These results showed that besides the invasive nature of both stages, we were able to detect stage-specific expressed genes and a distinct transcriptional profile. In merozoites, most of the differentially expressed genes were associated to translation, protein modification and folding, and binding processes. Conversely, sporozoites showed a very distinct transcription profile, with a low number of BLAST hits. Some of the identified products included histones and proteins associated with transport and catalytic activity. A preliminary 
experimental validation using real-time PCR was carried out with a small group of genes and the expression ratio observed between the tested developmental stages has been experimentally confirmed with a good correlation. A comparison analysis of the differential expressed genes obtained by LongSAGE and Northern Digital of ESTS/ORESTES also showed a good agreement, and many differentially expressed genes have been mutually identified by both techniques.

Keywords: Coccidiosis. Eimeria tenella. Gene Expression. Merozoites. Sporozoites. Expressed sequence tags. 
1 INTRODUÇÃO 


\subsection{Eimeria spp. e o Filo Apicomplexa}

Protistas do gênero Eimeria (Classe Coccidia, Filo Apicomplexa) foram de acordo com a história, os primeiros protozoários parasitas a serem visualizados. Em 1674, Antony van Leeuwenhoek, considerado um dos criadores do microscópio, descreveu a presença de corpúsculos nos dutos biliares de um coelho, os quais provavelmente tratavam-se de oocistos de Eimeria stiedae. Somente 150 anos mais tarde o primeiro membro deste filo foi taxonomicamente classificado (Levine, 1973).

O Filo Apicomplexa é composto por mais de 5.000 espécies de protozoários intracelulares obrigatórios são considerados os parasitas eucarióticos mais bem sucedidos do planeta. Dentro deste grupo, patógenos de importância médica e veterinária são responsáveis por grandes ameaças à saúde mundial causando prejuízos à economia global (Sibley, 2004; Tomley, 2009)

Dentre os parasitas de importância médica, podemos destacar o gênero Plasmodium, responsável pela malária, o Toxoplasma gondii que pode causar abortos e danos neurológicos congênitos e também os gêneros Cryptosporidium e Cyclospora que estão associados a infecções oportunísticas em indivíduos imunossuprimidos, particularmente os infectados pelo HIV (Roos, 2005; Striepen et al., 2002). Com relação aos patógenos de importância médico-veterinária, podemos citar os gêneros Babesia, Neospora, Theileria e Eimeria, que são capazes de infectar animais domésticos e de produção, acarretando em grandes prejuízos econômicos (Belli et al., 2005; Hu et al., 2006).

$\mathrm{Na}$ figura 1 podemos observar uma árvore filogenética de alguns gêneros do Filo Apicomplexa (Wu, 2008). Os organismos deste filo são caracterizados pela presença de uma combinação única de organelas na extremidade apical das formas "zoítas" (infectantes) destes parasitas, denominada de complexo apical (Levine, 1973; Tomley e Soldati, 2001). 


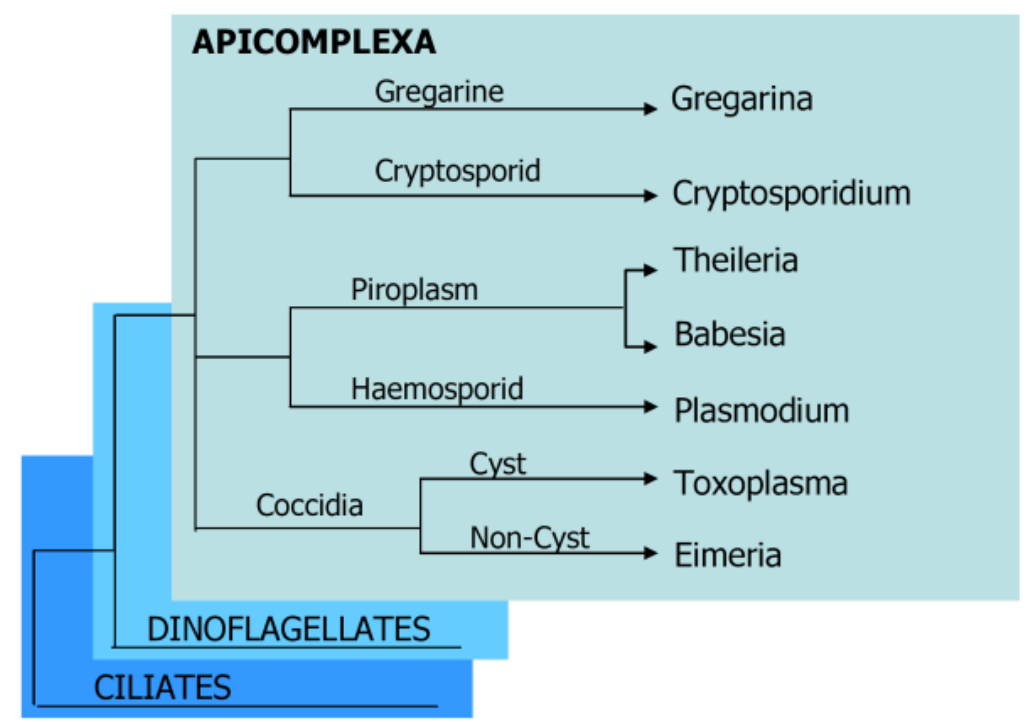

Figura 1 - Árvore filogenética de organismos do Filo Apicomplexa baseada nas seqüências da subunidade menor do RNA ribossômico.

Fonte: Wu, 2008.

O complexo apical é composto por um conóide, anéis polares, microtúbulos subpeliculares, roptrias, micronemas e grânulos densos. (Dubremetz et al., 1998; Santos et al., 2009). Estas estruturas estão associadas à motilidade, adesão e penetração dos parasitas nas células hospedeiras e formação do vacúolo parasitóforo (Bumstead e Tomley, 2000; Morrissette e Sibley, 2002). Os micronemas, roptrias e grânulos densos constituem um grupo de organelas secretoras que liberam seu conteúdo de forma seqüencial durante o processo de invasão. Inicialmente as micronemas secretam suas proteínas que estão envolvidas na motilidade, adesão e reconhecimento da célula hospedeira (Bumstead e Tomley, 2000; Tomley e Soldati, 2001). Em seguida há liberação das proteínas das roptrias, que auxiliam na movimentação do parasita para dentro da célula hospedeira e na formação da membrana do vacúolo parasitóforo (Sibley, 2004). Finalmente, os grânulos densos, que tem a função de remodelar o vacúolo parasitóforo tornando este compartimento metabolicamente ativo, liberam seu conteúdo (Bromley et al., 2003; Dubremetz et al., 1998; Entzeroth et al., 1998). O conóide (presente apenas nos coccídias), os anéis polares, e os microtúbulos subpeliculares, fazem parte do 
citoesqueleto celular, responsável por mediar o processo de invasão celular. O conóide é uma estrutura pequena na forma de cone, composta por filamentos espiralados e, acredita-se que esteja envolvida na função mecânica da invasão. Os anéis polares constituem um dos centros de organização dos microtúbulos subpeliculares, sendo ambos importantes para a manutenção da forma, polaridade e tráfico de organelas nestes organismos (Morrissette e Sibley, 2002; Santos et al., 2009).

Dentro deste filo há a classe Coccidia, grupo variado de parasitas cujas espécies podem ter ciclo de vida monoxênico ou heteroxênico, podendo ou não acometer uma grande gama de hospedeiros (Tenter et al., 2002). Dentro desta classe, o gênero Eimeria é o mais representativo do Filo Apicomplexa, com mais de 1700 espécies descritas (Levine, 1988), as quais podem ser encontradas em diversos hospedeiros, desde organismos invertebrados como anelídeos e insetos, até vertebrados, incluindo anfíbios, répteis, aves e mamíferos, que representam a grande maioria dos hospedeiros.

Os protozoários do gênero Eimeria apresentam um ciclo de vida direto (monoxênico) e grande parte destes organismos infectam as células epiteliais da mucosa intestinal. O ciclo de vida é dividido em esporogonia, que ocorre fora do hospedeiro sendo responsável pela formação do estágio infectante do parasita, a esquizogonia (reprodução assexuada) e a gametogonia (reprodução sexuada) as quais ocorrem dentro da célula de um hospedeiro espécie-específico (Kogut, 1990; Shirley e Harvey, 1996, 2000). Tyzzer (1929) foi o pioneiro na caracterização das espécies deste gênero e estabeleceu a base do estudo em coccídias, trabalhando com espécies de Eimeria que acometem as aves (Ball et al., 1989). 


\section{$1.2 \quad$ Coccidiose aviária}

\subsubsection{A doença e importância econômica}

Os protozoários do gênero Eimeria são responsáveis pela coccidiose aviária, uma doença entérica que acomete galinhas domésticas e é causada por sete espécies deste gênero: E. acervulina, E. maxima, E. tenella, E. necatrix, E. brunetti, E. praecox e E. mitis (Fernando, 1990). Economicamente, as espécies capazes de infectar a galinha doméstica são consideradas as mais relevantes do gênero Eimeria (Shirley et al., 2005).

Estes parasitas são cosmopolitas e, acometem principalmente frangos de corte e matrizes reprodutoras (Williams, 1998). Esta doença resulta em aumento da conversão alimentar, menor capacidade de absorção de nutrientes pelo trato intestinal, menor ganho de peso e, em alguns casos, aumento da mortalidade (Min et al., 2004).

Cada espécie se desenvolve em uma localidade específica do trato intestinal das aves (sítio-específica) e pode induzir diferentes graus de patogenicidade, variando de moderado até severo (Long e Joyner, 1984). A imunidade é espécieespecífica, ou seja, uma ave imune a uma espécie é suscetível às outras (Dalloul e Lillehoj, 2005) e, além disso, um único hospedeiro pode ser infectado por mais de uma espécie simultaneamente.

Apesar da disponibilidade de drogas anticoccidianas e de vacinas vivas para o controle desta doença, os prejuízos causados à indústria avícola são enormes. Grande parte dos custos está relacionada à profilaxia e tratamento, além de perdas com o aumento de mortalidade e queda da produção. Calcula-se que os gastos mundiais relacionados ao controle desta doença variem de 800 milhões (Allen e Fetterer, 2002) a 3 bilhões de dólares por ano (Shirley et al., 2004b).

A indústria avícola tem um papel fundamental na economia brasileira. O Brasil é o primeiro maior exportador e o terceiro maior produtor de carne de frango do mundo (Figura 2). O frango constitui o $3^{\circ}$ produto das exportações na área de agronegócios e $5^{\circ}$ produto brasileiro na pauta de exportação. Sendo exportado para 
mais de 150 países. Em 2008, a produção de carne de frango chegou a 10,9 milhões de toneladas das quais $67 \%$ foi consumida pelo mercado interno e as exportações resultaram em uma receita cambial de quase 7 bilhões de dólares.
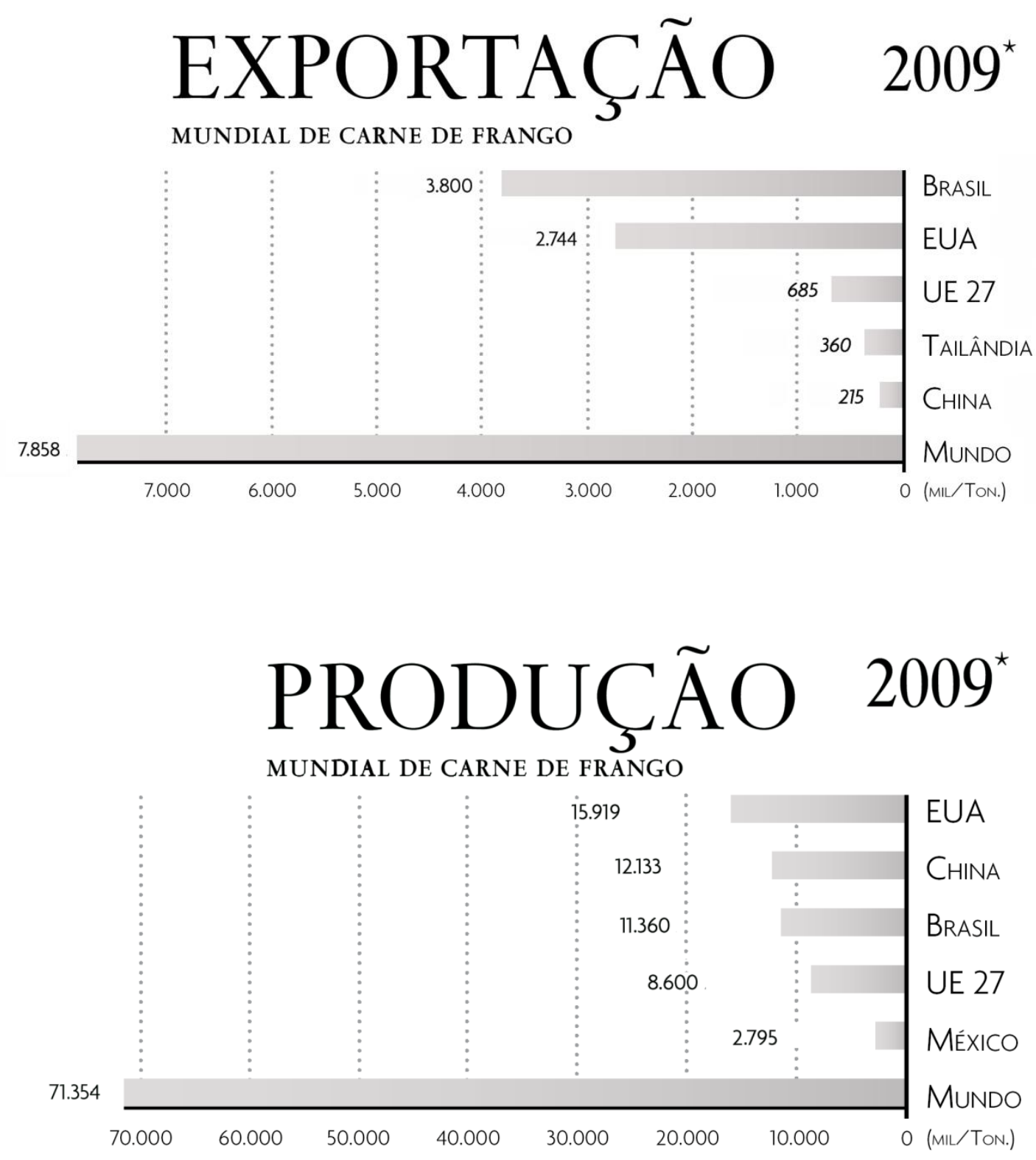

Figura 2 - Exportação (acima) e produção (abaixo) mundial de carne de frango, $\left(^{*}\right)$ projeção de 2009 em milhões de toneladas.

Fonte: Associação Brasileira dos Produtores e Exportadores de Frangos, Relatório Anual (ABEF) 2008-09. 


\subsubsection{Diagnóstico}

Tradicionalmente, as espécies de Eimeria são identificadas com base em critérios como dimensão e morfologia dos oocistos, especificidade do hospedeiro, sítios intestinais de colonização, características macro e microscópicas das lesões intestinais, localização tecidual e morfologia das formas evolutivas, período prépatente, especificidade imunológica e tempo mínimo de esporulação dos oocistos (Long e Joyner, 1984; Long et al., 1976). Estes parâmetros analisados de forma conjunta permitem a distinção entre as espécies, entretanto, exigem pessoal altamente treinado. Nem sempre este diagnóstico é confiável, uma vez que pode ocorrer sobreposição de características entre espécies distintas, principalmente em infecções mistas. Além disso, o uso de vacinas de cepas precoces tem limitado a utilização do período de pré-patência como critério de discriminação.

Uma vez que as características biológicas não são suficientemente precisas para se fazer a discriminação entre as espécies de Eimeria, novas técnicas baseadas em métodos moleculares têm sido desenvolvidas.

Os primeiros ensaios diagnósticos baseados em PCR (Polymerase Chain Reaction) foram realizados utilizando a técnica de RAPD (Random Amplified Polymorphic DNA) (Johnston e Fernando, 1995; MacPherson e Gajadhar, 1993; Shirley e Bumstead, 1994). Além de não ser adequado para diagnóstico de amostras mistas, a baixa confiabilidade e reprodutibilidade deste método, restringiram severamente seu amplo uso entre diferentes laboratórios.

Schnitzler et al. (1998; 1999) desenvolveram um teste diagnóstico utilizando como alvos de amplificação a região do espaçador ribossômico interno transcrito 1 (ITS1).

Nosso grupo também desenvolveu um conjunto de marcadores moleculares denominados SCARs (Sequence-Characterized Amplified Regions), os quais permitem o diagnostico de espécies por PCR, empregando primers específicos. Desenvolvido na forma de um PCR multiplex, este teste tem a grande vantagem de permitir o diagnostico das sete espécies simultaneamente em uma única reação (Fernandez et al., 2003).

Mais recentemente, alguns grupos desenvolveram diagnósticos moleculares 
baseados na técnica de PCR em tempo real (Blake et al., 2008; Kawahara et al., 2008; Morgan et al., 2009).

\subsubsection{Controle da doença}

As estratégias convencionais de controle desta doença baseiam-se principalmente no uso de drogas anticoccidianas, adicionadas na ração das aves de forma profilática ou quimioterápica (Williams, 1998). No entanto, o constante surgimento de cepas resistentes às drogas, aliada à preocupação do mercado consumidor com a contaminação dos alimentos com resíduos químicos, têm influenciado negativamente o uso de quimioterápicos (Dalloul e Lillehoj, 2005; Shirley et al., 2007).

As restrições legislativas à utilização destes fármacos têm crescido, limitando a quantidade, tempo de exposição e gama de medicamentos permitidos, principalmente na Europa e Estados Unidos, onde algumas drogas já foram totalmente banidas (Shirley et al., 2007). No Reino Unido, por exemplo, o número de anticoccidianos disponíveis comercialmente caiu de 17 em 2002, para apenas 10 em 2004. Em decorrência destas restrições, a última nova droga introduzida no mercado foi há mais de 10 anos.

Em detrimento ao uso de drogas, as vacinas vivas, compostas de cepas virulentas ou atenuadas de Eimeria são a única alternativa eficaz para o controle da coccidiose aviária (Williams, 1998). Estas vacinas são multivalentes (contém mais de uma espécie) já que a imunidade é espécie-específica e, geralmente, são compostas por cepas sensíveis às drogas. A primeira vacina lançada no mercado foi a Coccivac® (Schering-Plough) em meados de 1950, e permaneceu a única durante praticamente 35 anos. Atualmente, mais de 13 tipos de vacinas estão disponíveis no mercado (Chapman et al., 2002).

Em relação às vacinas compostas por cepas virulentas, para que não ocorra queda nos índices de produção e ocasionalmente, desenvolvimento de sintomas clínicos da doença (Shirley et al., 2005), a aplicação destas vacinas requer um controle rígido e a utilização de baixas doses. 
O uso de vacinas de cepas atenuadas oferece uma alternativa mais segura. Os períodos de pré-patência do ciclo destes parasitas são mais curtos, há redução de um ou mais ciclos de reprodução assexuada acarretando em uma diminuição da capacidade reprodutiva sem prejuízo da imunogenicidade (Allen e Fetterer, 2002; Shirley et al., 2007). No entanto, devido à baixa produção de oocistos, os custos de produção destas vacinas são muito maiores (Dalloul e Lillehoj, 2005).

Um sério problema relativo ao uso de vacinas vivas refere-se à imunovariabilidade entre cepas de uma mesma espécie o que muitas vezes não confere proteção cruzada, como é o caso de algumas cepas de E. maxima (Shirley et al., 2004a; Smith et al., 2002). Por exemplo, a vacina Paracox® (Schering-Plough) possui duas cepas de E. maxima em sua formulação.

\subsection{A Eimeria tenella como modelo de estudo da coccidiose aviária}

\subsubsection{Caracterização}

Desde o trabalho pioneiro de Tyzzer (1929), a E. tenella tem sido considerada como modelo de estudo para o entendimento da coccidiose aviária (Chapman e Shirley, 2003). Esta espécie apresenta alta prevalência no campo, alta virulência, facilidade de obtenção de formas invasivas (zoítas) e de oocistos diretamente dos cecos, alta taxa de replicação e de esporulação, além de ser a única espécie capaz de ser propagada in vitro (Chapman e Shirley, 2003; Ling et al., 2007). A cepa Houghton (H), isolada no Reino Unido em 1949, cuja linhagem de origem clonal foi obtida em 1986, é uma das poucas cepas de referência usadas para estudos experimentais (Chapman e Shirley, 2003; Ling et al., 2007). Recentemente, alguns artigos relatando a transfecção estável em Eimeria tenella foram publicados, no entanto, para seleção de transfectantes, ainda é necessária a utilização de passagens in vivo (Clark et al., 2008; Shi et al., 2009; Yan et al., 2009; Zou et al., 2009). 
E. tenella é altamente patogênica, provocando perda de peso, diarréia com sangue e até mortalidade das aves (de Venevelles et al., 2004). Coloniza prioritariamente os cecos (Figura 3A), onde há o desenvolvimento de lesões hemorrágicas e, em casos severos há necrose tecidual associada à formação de coágulos sanguíneos. As lesões também podem ser observadas na superfície serosa dos cecos (Figura 3B).

Este parasita é caracterizado por um ciclo de vida direto (monoxênico), com vários ciclos intestinais endógenos envolvendo estágios assexuados (merogonia ou esquizogonia), seguidos de um estágio sexual (gamogonia ou gametogonia) que resulta na formação de um oocisto não esporulado (Shirley e Harvey, 2000). Os oocistos esporulados (Figura 3C), assim como em todos os organismos do gênero Eimeria, apresentam 4 esporocistos, com 2 esporozoítos cada.

A

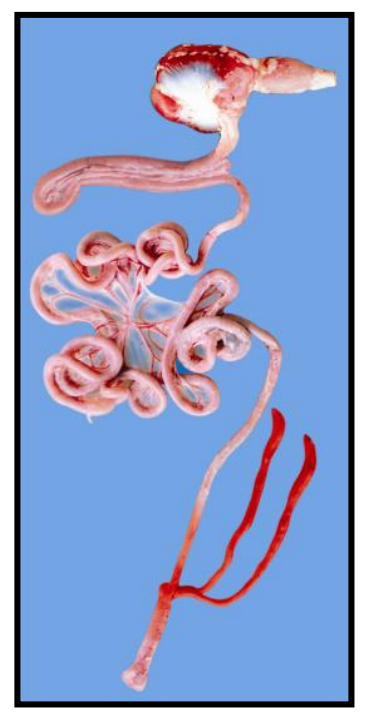

B

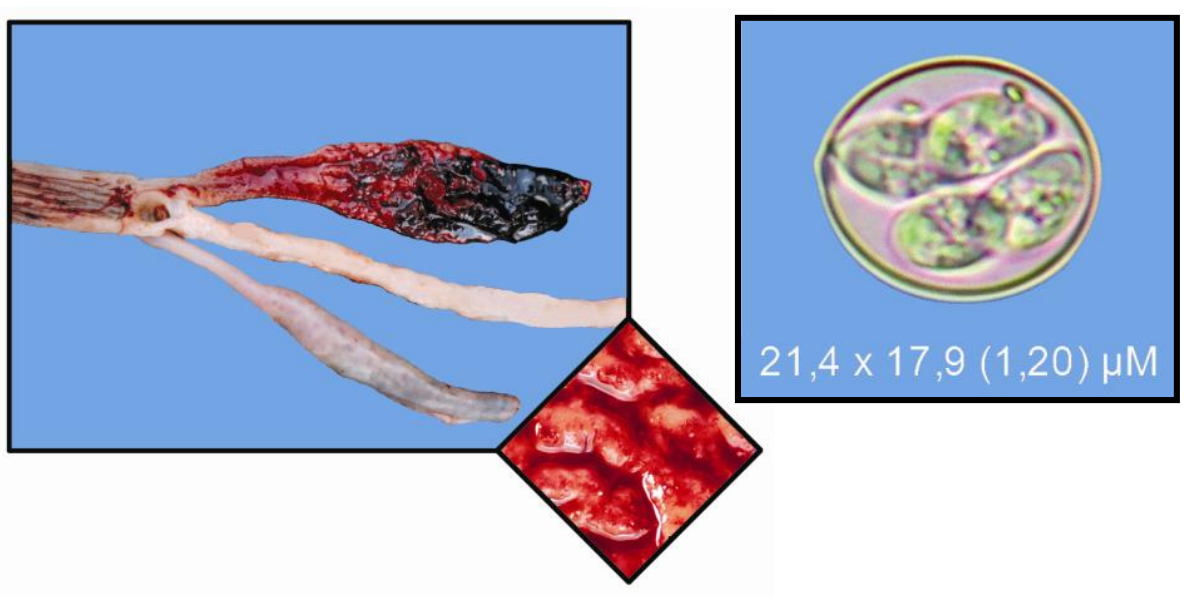

Figura 3 - Eimeria tenella: sítio da lesão intestinal, lesão macroscópica e oocisto. (A) Os cecos, destacados em vermelho constituem o sítio de colonização desta espécie, (B) lesões hemorrágicas nos cecos podem ser visualizadas tanto na mucosa quanto na serosa. (C) Oocisto de E. tenella, com as medidas de tamanho referentes ao diâmetro maior e menor e a razão entre eles (entre parênteses). 


\subsubsection{Ciclo de vida}

O ciclo de vida de Eimeria tenella (Figura 4) é iniciado quando uma ave suscetível ingere um oocisto esporulado (Etapa 1). Este oocisto é rompido fisicamente pela ação da moela liberando os esporocistos. Os esporocistos, no intestino delgado, são submetidos à ação de sais biliares e tripsina que digerem o corpúsculo de Stieda (localizado em uma das extremidades do esporocisto), abrindo um pequeno orifício por onde os esporozoítos saem ativamente (Etapa 2), processo este denominado de excistação.
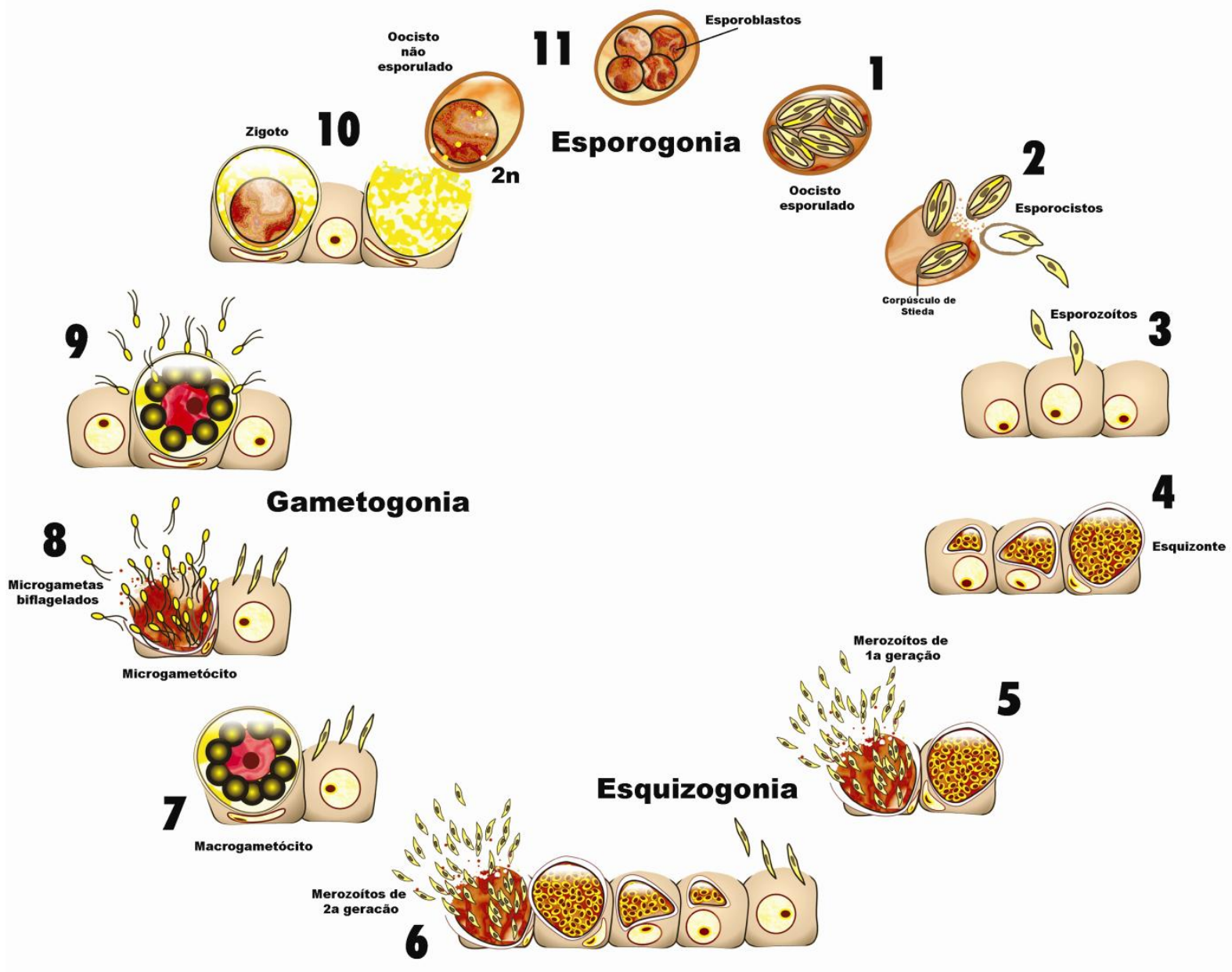

Figura 4 - Ciclo de vida de Eimeria tenella (Arte Gráfica: Helton Barreiro). 
Os esporozoítos, em seguida, são carregados até as criptas cecais por linfócitos intra-epiteliais, onde aderem e invadem as células epiteliais e da submucosa (Etapa 3), diferenciando-se em seguida em formas esquizontes.

Os esquizontes passam por um ciclo de reprodução assexuada denominada de esquizogonia (merogonia), que consiste em múltiplas divisões mitóticas sem citocinese que geram esquizontes multinucleados (Etapa 4) os quais se diferenciam em merozoítos uninucleados de 1a geração. Com o rompimento destas células, os merozoítos de 1a geração são liberados (Etapa 5), invadem novas células (Etapa 6), formando em seguida o esquizonte de $2^{2}$ geração.

Após 3 ou 4 ciclos de reprodução assexuada (esquizogonia), cada merozoíto pode se diferenciar em macrogametócito (Etapa 7) ou microgametócito (Etapa 8). Os microgametócitos se rompem liberando os microgametas biflagelados que fertilizam os macrogametas (Etapa 9), resultando na formação de um zigoto (único estágio diplóide do parasita). O zigoto é coberto por camadas multilamelares que irão constituir a parede do oocisto. Uma vez maduro o oocisto não esporulado é liberado no ambiente juntamente com as fezes (Etapa 10). Sob condições ideais de temperatura (entre $26-28^{\circ} \mathrm{C}$ ), umidade e oxigenação, o oocisto passa por uma etapa de reprodução assexuada (esporogonia), também conhecida como esporulação. Durante este processo, o oocisto não esporulado (diplóide) sofre uma meiose, gerando 4 esporoblastos haplóides (Etapa 11), cada um, após uma divisão mitótica, dá origem aos esporocistos com dois esporozoítos cada (Current et al., 1990; Fernando, 1990; Hammod, 1973; Kinnaird et al., 2004; Schmatz, 1997).

\subsubsection{Caracterização do genoma}

O genoma nuclear de Eimeria spp. é haplóide durante a maior parte do ciclo de vida deste parasita, com exceção do zigoto. A cepa $\mathrm{H}$ de Eimeria tenella tem sido utilizada amplamente para os estudos de caracterização molecular e determinação do genoma destes organismos.

O material genômico haplóide está organizado em 14 cromossomos, que variam de tamanho entre 1,0 a mais de 7,0 Mpb, determinado através de 
eletroforese de campo-pulsado (PFGE - pulsed-field gel electrophoresis) (Shirley, 2000, 1994). O genoma possui uma complexidade de cerca de 55 milhões de pares de bases (Ling et al., 2007) e conteúdo GC de 53\% (Shirley, 2000).

O genoma da cepa $\mathrm{H}$ de $E$. tenella foi seqüenciado empregando a abordagem shotgun com uma cobertura de 8,4 vezes e os dados estão publicamente disponíveis no sítio do Instituto Sanger (http://www.sanger.ac.uk/Projects/E tenella/). Esta iniciativa foi patrocinada pelo BBSRC (Biotechnology and Biological Sciences Research) e realizada pelo WTSI (Wellcome Trust Sanger Institute, Cambridge, Inglaterra), em colaboração com o IAH (Institute for Animal Health, Compton, Inglaterra).

Além do genoma, o cromossomo 1 desta espécie foi totalmente seqüenciado (Ling et al., 2007). Este cromossomo possui uma organização genômica incomum segmentada em regiões $\mathrm{R}$ (feature-rich), que são ricas em repetições, apresentando elementos similares a transposons e repetições teloméricas, confirmando estudos preliminares que apontavam para uma distribuição freqüente de regiões repetitivas no genoma de Eimeria tenella (Shirley, 2000; Shirley et al., 2004b). Também apresenta segmentos livre de repetições $P$ (feature-poor) (Ling et al., 2007).

Grande parte das repetições seriadas do trinucleotídeo CAG e do heptâmero AGGGTTT estão presentes nas 3 regiões de segmentos $R$, que são separadas por 4 regiões de segmentos $P$. Os microssatélites CAG são encontrados preferencialmente em regiões codificadoras, enquanto que as seqüências do heptâmero, identificadas como unidades repetitivas teloméricas em Plasmodium, são encontradas nas pontas da seqüência consenso, assim como nas regiões intrônicas e intergênicas do segmento R. Além destes, há também o octâmero palíndromo TGCATGCA, aparentemente único em apicomplexas, que está presente 157 vezes das quais grande parte estão em regiões intergênicas do segmento $R$. As duplicações gênicas em sua grande maioria estão associadas aos segmentos $P$ e podem conter genes, enquanto que as duplicações detectadas nos fragmentos $R$ são geralmente pequenas e associadas às regiões similares a telômeros (Ling et al., 2007).

Além do genoma nuclear, estão presentes nestes parasitas, dois genomas extracromossômicos: o mitocondrial e o do apicoplasto. Estes protozoários apresentam uma única mitocôndria de formato tubular e o genoma é constituído de 
concatâmeros lineares contendo unidades repetitivas de 6kb (Chapman e Shirley, 2003; Romano, 2004). O apicoplasto é uma organela exclusiva dos organismos do Filo Apicomplexa, homóloga aos cloroplastos das plantas, não possuindo atividade fotossintética (Waller e McFadden, 2005). O genoma desta organela em Eimeria tenella é circular, rico em conteúdo AT e contém cerca de 35 kb (Cai et al., 2003).

\subsection{Métodos de análise da expressão gênica}

A geração de seqüências de DNA genômico tem sido de grande utilidade para a caracterização molecular de organismos. No entanto, o conhecimento destas seqüências não é suficiente para a caracterização inequívoca dos genes expressos. Para um melhor entendimento da biologia dos parasitas, diversos estudos sobre expressão gênica têm sido realizados (Ojopi et al., 2007; Skuce et al., 2005).

O modelo de genes eucarióticos é extremamente complexo conforme ilustrado e descrito na Figura 5.

Considerando que as proteínas constituem o produto final da função gênica, o estudo destas representa a forma mais direta de avaliação dos genes expressos. Como existem várias estudos que indicam que a quantidade de proteína produzida pode ser diretamente proporcional à quantidade de RNAm (RNA mensageiro) que a codifica (Yamamoto et al., 2001) a medição dos níveis de RNAm pode também ser utilizada para o estudo de função e anotação dos genes (Sun et al., 2004).

Os métodos para a análise de expressão gênica evoluíram rapidamente em poucos anos. Tradicionalmente, a avaliação do nível de um RNAm transcrito era realizada empregando-se métodos como o Northern blot e RT-PCR (Reverse Transcriptase PCR) semi-quantitativo, utilizando-se seqüências de DNAs complementares (cDNAs) transcritas reversamente a partir das amostras de RNA mensageiros, as quais representam uma fonte direta para a descoberta de regiões codificadoras de genes. 


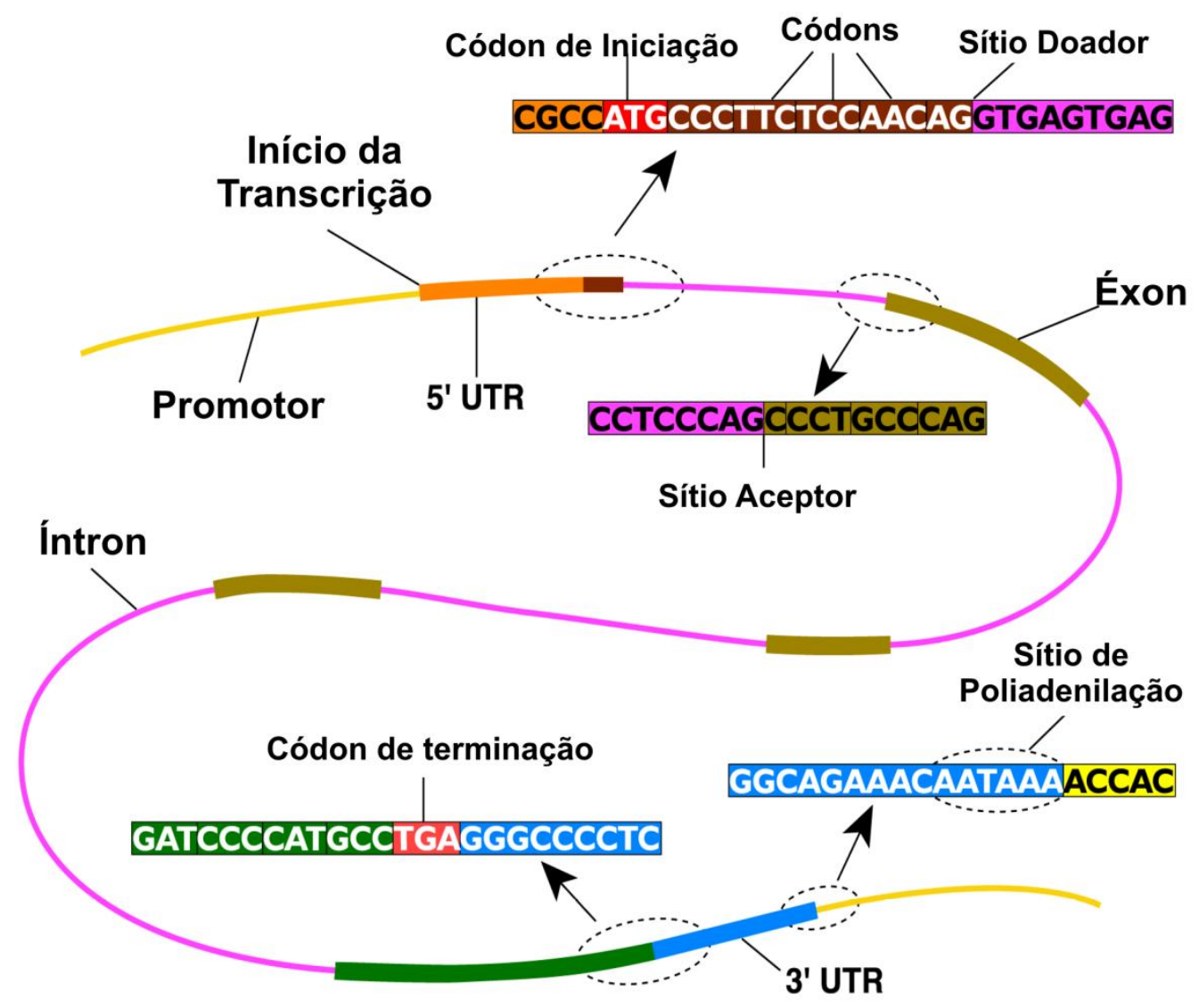

Figura 5 - Esquema do modelo gênico de eucariotos. A linha contínua corresponde à seqüência de DNA. As regiões intergênicas estão nas extremidades em amarelo. O gene começa com o sítio de início da transcrição, e o final é representado pelo sítio de poliadenilação. As barras que estão na linha representam os éxons do gene, enquanto que as linhas em rosa são os íntrons (não transcritos). As junções entre éxons e íntrons são sítios de splicing denominados de sítio doador e sítio aceptor. A tradução do transcrito é iniciada no códon de iniciação e finalizada no códon de terminação originando o produto gênico. As barras em laranja e azul correspondem às regiões não traduzidas (UTRs).

Fonte: Adaptado de Wu, 2008.

Em 1991 Adams et al. descreveram uma abordagem para obtenção e sequenciamento de pequenas seqüências expressas, denominadas de ESTs (Expressed Sequence Tags) que permitem avaliar o perfil transcricional de um subconjunto de genes expressos. Milhares de seqüências de ESTs foram geradas para vários organismos em diferentes tecidos ou estágios (Nagaraj et al., 2007). 
Basicamente, para a geração de ESTs, clones de bibliotecas de cDNA são selecionados randomicamente e submetidos a um sequenciamento de uma única fita (single-pass) gerando seqüências curtas de aproximadamente 300-600 pb que podem ser obtidas a partir de um tecido, ou estágio específico de desenvolvimento de um organismo. As bibliotecas convencionais podem ser construídas a partir da região 5' ou 3' dos transcritos, utilizando-se adaptadores que permitem a clonagem unidirecional. As bibliotecas direcionais 5' apresentam maior cobertura de regiões codificadoras, facilitando a identificação de genes desconhecidos. No entanto, as bibliotecas 3', que geralmente identificam as porções não traduzidas (3'UTR Untranslated Regions) apresentam maior variabilidade do que as regiões codificadoras e permitem a identificação inequívoca destes transcritos, facilitando a obtenção de um perfil de transcrição quantitativo (Gruber, 2007). Bibliotecas de ESTs também podem ser construídas de maneira alternativa empregando a técnica ORESTES (Open Reading Frame EST). Este método baseia-se em PCR de baixa estringência utilizando primers arbitrários para amplificação dos cDNA (Dias Neto et al., 2000), resultando desta forma, em uma maior cobertura da região central da sequência dos RNAs mensageiros, a qual contém a maior parte da porção codificadora dos genes. Como estas bibliotecas são normalizadas, aumenta-se a probabilidade de detecção de transcritos raros. Importante salientar que apenas bibliotecas não normalizadas podem refletir quantitativamente os níveis de expressão dos transcritos (Moody, 2001). Entretanto, a detecção de transcritos de baixa abundância é limitada, principalmente nas bibliotecas não normalizadas (Alba et al., 2004; Sun et al., 2004). Além disso, a cobertura dos transcritos em sua maioria é parcial, sujeita a erros e, muitas vezes, devido à freqüência heterogênea dos transcritos, pode ser altamente redundante e enviesada (Gruber, 2007; Li et al., 2003; Nagaraj et al., 2007).

A geração de ESTs tem contribuído de maneira significativa para a identificação de novos genes, determinação das regiões codificadoras das sequências genômicas (fronteiras íntron-exon), mapeamento físico, assim como análise de perfil de expressão (Sterky e Lundeberg, 2000). Além disso, ESTs que compartilham trechos em comum podem ser agrupadas e montadas, permitindo muitas vezes a identificação de sequências completas de RNAs mensageiros (Kozian e Kirschbaum, 1999). 
Técnicas de hibridização subtrativa de bibliotecas de cDNA permitiram um avanço na análise dos padrões de expressão gênica, constituindo um dos primeiros métodos a serem utilizados para detectar genes diferencialmente expressos em larga escala. Basicamente, os genes diferencialmente expressos são isolados pela hibridização de duas amostras de cDNAs: uma amostra em excesso (teste) e uma segunda amostra (controle). Os transcritos expressos em ambas as amostras formam uma molécula híbrida, enquanto que as moléculas exclusivamente expressas na amostra teste permanecem em forma de fita simples, estas últimas, são isoladas podendo ser utilizadas para a construção de bibliotecas de cDNA (Moody, 2001). A técnica de hibridização subtrativa de cDNAs começou a ser utilizada na década de 80 sendo aprimorada anos mais tarde de forma a incluir uma etapa de PCR, a qual foi denominada de Supression Subtractive Hybridization (SSH) (Diatchenko et al., 1996). Nesta variação, a etapa de amplificação é direcionada de forma a amplificar apenas as seqüencias de genes diferencialmente expressos.

Além dos métodos subtrativos, a geração de fingerprinting de RNA também foi uma das primeiras abordagens de seleção de genes de interesse (diferencialmente expressos) e incluem o Differential Display (DD) (Liang e Pardee, 1992) e o RNA fingerprinting by arbitrary primed PCR (RAP_PCR) (Welsh et al., 1992). O DD é baseado na conversão do RNAm em cDNA (duas ou mais amostras a serem comparadas), utilizando oligo dT primers, em seguida, o cDNA é amplificado empregando-se oligo dT primers e primers arbitrários. As amostras são separadas por tamanho em gel de poliacrilamida avaliando-se a presença ou ausência de bandas, assim como bandas de diferentes intensidades as quais podem representar potenciais transcritos diferencialmente expressos. Estas bandas são excisadas, os transcritos são clonados e seqüenciados (Moody, 2001). Apesar de largamente utilizada, esta técnica apresenta um alto índice de falsos positivos (Green et al., 2001). O RAP-PCR é uma abordagem muito semelhante ao DD, que ao invés de usar oligo dT primers para síntese de cDNA utiliza primers arbitrários de $10 \mathrm{pb}$, o que permite a utilização de RNA total nos ensaios experimentais (Avison, 2008). Estes métodos apresentam bons resultados e ainda são usualmente empregados, no entanto, possuem uma limitação quanto ao número de transcritos que podem ser analisados simultaneamente, além disso, são capazes de gerar 
apenas um retrato parcial sem informação direta a respeito da abundância destes genes.

Recentemente, outros métodos de análise de expressão gênica foram desenvolvidos incluindo SAGE (Serial Analysis of Gene Expression), MPSS (Massive Pararell Signature Sequencing), e Microarrays (van Ruissen et al., 2008). Atualmente, os métodos de análise de expressão gênica são divididos em dois grupos: sistemas de plataformas abertas ou fechadas.

Uma plataforma é considerada fechada, quando os genes que determinam o espaço da investigação são finitos, e, portanto, para utilização destas técnicas é necessário o conhecimento prévio das seqüências a serem utilizadas o que depende da disponibilidade de informações do organismo a ser estudado (Green et al., 2001). Os métodos mais amplamente utilizados são os de microarrays, classificados como plataformas fechadas de larga escala baseadas em hibridização. Os mais conhecidos são os microarrays de cDNA (Schena et al., 1995), de oligonucleotídeos (Pease et al., 1994) e os Affymetrix chips comercialmente disponíveis que sintetizam centenas de sondas de oligonucleotídeos in situ (diretamente nos chips) utilizando um método fotolitográfico (http://www.affymetrix.com/index.affx). O PCR em tempo real (Real time PCR ou qPCR, quantitative PCR) (Heid et al., 1996), é também considerado como uma plataforma fechada, porém de baixa escala.

Um microarray é tipicamente definido como um arranjo pré-definido de moléculas (fragmentos de DNA, cDNAs ou oligonucleotídeos) quimicamente ligadas (ligações covalentes) a uma superfície sólida ou a uma membrana (carregada positivamente). A superfície sólida pode ser de vidro ou de silicone (Affy chip Affymetrix), ou conter orifícios microscópicos na superfície (Illuminahttp://www.illumina.com/pages.ilmn?ID=5). O princípio deste método baseia-se na hibridização entre as sondas que compõem estes microarranjos com o gene ou molécula de interesse. A ligação dos alvos marcados com fluoróforos permite a detecção e quantificação das moléculas hibridizadas. Em seguida, uma imagem de hibridação é gerada e detectada por meio de leitores (scanners) (Dufva, 2009; Jaluria et al., 2007).

Centenas a milhares de sondas (genes) podem ser testadas em um único experimento, o que torna a tecnologia de microarray bastante atraente e amplamente utilizada. No entanto, como qualquer outra técnica, apresenta 
limitações. Por se tratar de um método de hibridização, são necessárias replicatas experimentais (normalmente duas), além disso, os dados de fluorescência somente detectam a presença ou ausência das moléculas hibridizadas, não fornecendo nenhuma outra informação a respeito do tamanho ou composição dos alvos capturados. Problemas relativos à hibridização cruzada (famílias de genes contendo seqüências muito semelhantes) ou inespecífica são inerentes à técnica, já que moléculas de diferentes tamanhos e composições são simultaneamente submetidas ao processo. Assim, a escolha correta das sondas é de fundamental importância para o sucesso do experimento, bem como a utilização de análise estatística complexa para interpretação dos dados de fluorescência. Como diferentes marcadores, métodos de hibridização e construção dos arrays podem ser empregados, a comparação inter-plataformas é uma tarefa difícil. Medições de expressão gênica absolutas somente são obtidas através de microarrays de oligonucleotídeos (single-channel), enquanto que as outras tecnologias, em geral, são relativas (dual-channel) (Dufva, 2009; Jaluria et al., 2007).

O PCR em tempo real tornou-se um procedimento muito bem estabelecido para quantificação de níveis de expressão gênica. Esta técnica baseia-se na detecção da quantidade de produto amplificado em cada ciclo da reação empregando-se fluoróforos (Ponchel, 2006). Para tal, diferentes estratégias podem ser utilizadas como substâncias fluorescentes intercalantes de DNA (SYBR ${ }^{\circledR}$ Green) ou uso de sondas marcadas. O SYBR ${ }^{\circledR}$ Green possui a propriedade de emitir fluorescência quando ligado às moléculas de DNA dupla fita e é amplamente utilizado, devido ao seu baixo custo, facilidade de uso e sensibilidade. Como este corante se liga a qualquer molécula dupla-fita de DNA, como dímeros de primers ou produtos inespecíficos, a concentração do fragmento alvo pode ser superestimada (Kubista et al., 2006; Ponchel, 2006). Este problema pode ser minimizado empregando-se primers que não formem dímeros e que sejam mais específicos. O TaqMan® (sondas de hidrólise) utiliza sondas que apresentam em sua extremidade um fluoróforo repórter, e na outra extremidade um fluoróforo aceptor (quencher), que quando ligados na mesma molécula não emitem fluorescência, pois o fluoróforo aceptor absorve o sinal emitido pelo repórter. Durante a amplificação e sob a atividade de exonuclease da Taq DNA polimerase, a sonda de oligonucleotídeos é clivada, o repórter e o aceptor são separados, permitindo a detecção da 
fluorescência emitida pelo fluoróforo repórter. O princípio da detecção da fluorescência é similar ao do SYBR ${ }^{\circledR}$ Green no qual os produtos amplificados são mensurados a cada ciclo de amplificação. Como somente a fluorescência emitida pelas seqüências alvo é mensurada, a tecnologia TaqMan ${ }^{\circledR}$ é mais específica (Bell e Ranford-Cartwright, 2002; Valasek e Repa, 2005). Existem outras variações da utilização de um repórter e um quencher, baseados em sondas de hidrólise, incluindo molecular beacons, sunrise primers e scorpion primers, entretanto os custos são maiores. Há também sondas baseadas em um único corante, na qual a fluorescência é detectada de acordo com a ligação ao DNA, tais como as sondas LightUp, que possuem em sua estrutura um ácido nucléico peptídico neutro (PNA) que se liga ao DNA com maior afinidade do que os oligonucleotídeos comuns (Kubista et al., 2006; Valaseq e Repa, 2005).

Na técnica de real time $P C R$, os métodos de quantificação podem ser classificados como absolutos ou relativos. Na quantificação absoluta há a construção de uma curva padrão baseada na diluição de uma molécula de concentração conhecida, enquanto que nas abordagens relativas à determinação da diferença de expressão é calculada em relação a um grupo experimental de amostras controle (Peirson et al., 2003). Apesar da alta sensibilidade, a ampla utilização da técnica de PCR em tempo real ainda é limitada devido ao alto custo e baixo throughput.

Um dos grandes desafios da chamada era pós-genômica está na elucidação do transcriptoma dos organismos o qual depende de predições computacionais e de seqüências previamente caracterizadas (que podem estar incompletas ou mal anotadas). A utilização das plataformas abertas de larga escala pode acelerar estes estudos e melhorar a qualidade do conhecimento obtido até o momento (Harbers e Carninci, 2005). Estas plataformas não necessitam de um conhecimento a priori do transcriptoma a ser estudado permitindo desta forma, a descoberta de novos genes. Além disso, não são limitadas a uma possível complexidade inerente destes transcritos, como por exemplo, a presença de SNPs (Single Nucleotide Polymorphims), de splicing alternativo, entre outros (Green et al., 2001).

Dentre as plataformas abertas de larga escala destacam-se o SAGE (Serial Analysis of Gene Expression) e suas variações (microSAGE, miniSAGE, LongSAGE, superSAGE, etc) e o MPSS (Massive Pararell Signature Sequencing), considerados 
como métodos de perfil de expressão digital, pois os dados de expressão gênica obtidos são analisados utilizando-se a contagem dos transcritos (freqüência). A contagem é uma medida simples e estatisticamente fácil de modelar. A expressão dos transcritos é medida em termos absolutos, permitindo uma análise global da expressão gênica.

O MPSS (Brenner et al., 2000; Reinartz et al., 2002) baseia-se na produção de sequências (signature sequences) de 16-20 bases adjacentes ao sítio de restrição da enzima Dpnll mais próximo à extremidade 3' do RNAm. Este método, no entanto, possui peculiaridades quanto à manipulação bioquímica e estratégia de sequenciamento, combina clonagem e amplificação de cDNA in vitro na superfície de milhares de microbeads a uma alta capacidade de sequenciamento de DNA não baseada em gel. Em cada microbead há a ligação de apenas uma molécula de cDNA. Após a hibridização, as seqüências alvo são clonadas obtendo-se cerca de 100.000 fragmentos de cDNA idênticos. Para o sequenciamento, os microbeads são posicionados em uma plataforma de análise e ligados a um adaptador (contendo 0 sítio de reconhecimento para a enzima do tipo Ils). Cada bead é digerido de forma seqüencial com esta enzima que cliva o DNA de forma a deixar uma extremidade coesiva de 4 nucleotídeos. Adaptadores fluorescentes (possuindo todas as combinações possíveis dos 4 nucleotídeos) são ligados as extremidade coesivas. A imagem é captada por uma câmera e analisada por um software capaz de processar os sinais de fluorescência durante as etapas de hibridização, ligação e clivagem determinando a sequência destes 4 nucleotídeos. O processo todo é repetido algumas vezes, até a obtenção das sequências de 16-20 nucleotídeos. Cada experimento pode gerar cerca de 250.000 - 400.000 sequências. Como esta tecnologia é baseada em instrumentos sofisticados e protegida por direitos autorais, seu custo é elevado, sendo disponível apenas comercialmente inicialmente pela Lynxgxgen Therapeutica, Inc., e posteriormente pela Solexa Inc., que encerrou esta prestação de serviço em 2006.

SAGE (Velculescu, 1999; Velculescu et al., 2000; Velculescu et al., 1995; Velculescu et al., 1997) é uma técnica que envolve o isolamento de pequenas seqüências de nucleotídeos, denominadas tags (etiquetas), que são concatenadas, seqüenciadas e quantificadas (Tuteja e Tuteja, 2004). Cada tag consiste de $4 \mathrm{pb}$ da seqüência de reconhecimento (CATG) da enzima de restrição Nlalll e 10 pb de 
seqüência adjacente na direção da cauda poliA de uma molécula de RNAm (Patankar et al., 2001). Cada tag representa uma seqüência expressa e a contagem de cada tag é diretamente proporcional à sua freqüência em uma dada população de RNAm (Dinel et al., 2005). Além de permitir a descoberta de novos transcritos (Rivals et al., 2007), SAGE permite a identificação de transcritos de baixa abundância (Chen et al., 2002; Kim et al., 2006), com uma sensibilidade 26 vezes maior do que ESTs (Sun et al., 2004).

A caracterização de transcritos diferenciais, resultantes de splicing alternativo (Khattra et al., 2007; Kuo et al., 2006; Wahl et al., 2005a), poliadenilação heterogênea (Keime et al., 2007; Ojopi et al., 2007), SNPs (Single nucleotide polymorphisms) (Radke et al., 2005; Silva et al., 2004), transcritos antisense (Patankar et al., 2001; Quére et al., 2004; Wahl et al., 2005b; Williams et al., 2007) e, até mesmo microRNAs (Ge et al., 2006) também pode ser obtida através da análise dos dados de SAGE.

O SAGE tem sido utilizado com sucesso em diversos organismos, tanto para a obtenção de perfis de expressão gênica, assim como na identificação de genes diferencialmente expressos, incluindo estudos em humanos (Keime et al., 2007), principalmente relacionados a câncer (Boon et al., 2002; Kirschbaum-Slager et al., 2005; Silveira et al., 2008), em organismos modelos como ratos (Wahl et al., 2005a, 2005b), Saccharomyces cerevisiae (Velculescu et al., 1997), Caenorhabditis elegans (Jones et al., 2001; Wang et al., 2009), Danio rerio (zebrafish) (Knoll-Gellida et al., 2006), Arabidopsis spp. (Fizames et al., 2004; Robinson e Parkin, 2008). Esta técnica também foi aplicada em estudos de parasitas, como Schistossoma mansoni (Ojopi et al., 2007; Taft et al., 2009; Williams et al., 2007), Leishmania spp. (Guerfali et al., 2008; Li et al., 2008), Haemonchus contortus (Skuce et al., 2005) e Giardia lamblia (Palm et al., 2005).

Dentro do Filo Apicomplexa estudos em Plasmodium falciparum (Munasinghe et al., 2001; Patankar et al., 2001), esporozoítos de Plasmodium berguei encontrados na glândula salivar de mosquito (Rosinski-Chupin et al., 2007) e Toxoplasma gondii (Radke et al., 2005) também utilizaram a plataforma SAGE. Estes estudos revelaram alta expressão de transcritos estágio específicos, detecção de genes mitocondriais, tags antisense, poliadenilação alternativa, além da caracterização de novos genes. Em Toxoplasma, foram construídas bibliotecas de 
SAGE utilizando taquizoítos das 3 cepas de referência deste organismo (tipo 1 - $\mathrm{RH}$, tipo 2 - Me49B7 e tipo 3 - VEGmsj). A partir da cepa VEG foi também realizado um estudo detalhado de seis fases do ciclo de vida, como oocistos, e várias fases de reprodução assexuada até a diferenciação em bradizoítos. Foram encontrados diferentes conjuntos de RNAm quando comparados a eucariotos superiores ou eucariotos unicelulares, como Saccharomyces. Foi observado que menos de $5 \%$ dos genes representam cerca de $75 \%$ dos transcritos totais. Diversos genes apicomplexa específicos foram encontrados nas classes de genes mais expressos. Segundo os autores, a transcrição nestes parasitas parece ser bastante dinâmica, com um alto número de genes expressos exclusivamente em um único estágio de desenvolvimento, demonstrando a importância da regulação transcricional.

Um aprimoramento desta técnica é o LongSAGE que ao invés de tags de $14 \mathrm{pb}$, gera tags com $21 \mathrm{pb}$, facilitando desta forma a predição in silico e a anotação gênica (Bianchetti et al., 2007; Saha et al., 2002). Por serem mais longas, o mapeamento das tags no transcriptoma e no genoma é mais específico, (Akmaev e Wang, 2004; Wahl et al., 2004; Wahl et al., 2005a) quando comparado ao SAGE convencional (Li et al., 2006; Lu et al., 2004), possui maior sensibilidade e cobertura gênica do que MPSS (Hene et al., 2007), além de ser a técnica de larga escala como menor índice de viés composicional GC (Margulies et al., 2001; Siddiqui et al., 2006).

\subsection{Base de dados de GO (Gene Ontology) e KOG (euKaryotic Orthologous Groups)}

O conhecimento da função biológica de uma determinada proteína em um dado organismo pode ajudar a inferir a sua função em outros organismos. Genes ortólogos são genes presentes em diferentes espécies derivados de um ancestral comum, e que normalmente retém essa mesma função no decorrer da evolução, enquanto que parálogos estão relacionados a eventos de duplicação (Koonin, 2005; Tatusov et al., 1997). A comparação de novos dados com proteínas conhecidas é importante para anotação, e, conseqüentemente, atribuição da função de produtos 
gênicos ainda não caracterizados. As bases de dados de GO e KOG são atualmente muito utilizadas para este tipo de busca e possuem a grande vantagem de serem curadas, o que aumenta a confiabilidade de suas informações, no entanto, apresentam um menor volume de dados.

Com o objetivo de estabelecer um vocabulário controlado comum, estruturado, dinâmico, precisamente definido e padronizado para a descrição das funções dos produtos gênicos em quaisquer organismos, em 2000, foi criado o consórcio de Ontologia Gênica (GO) (Ashburner et al., 2000). A classificação de GO é estruturada em três ontologias de termos para descrever: a função molecular, o processo biológico e o componente celular dos produtos protéicos. A função molecular descreve a função normalmente exercida pelo produto gênico, como por exemplo, structural molecule activity (atividade molecular estrutural), o processo biológico classifica o processo em que o produto protéico está envolvido, como metabolic process (processo metabólico) e o componente celular, descreve a localização celular onde o produto ocorre, por exemplo, organelle (organela) (Dimmer et al., 2008). Uma mesma proteína pode estar classificada dentro das três ontologias, refletindo a realidade biológica desta em particular, que pode funcionar em diferentes processos, conter domínios que carregam diversas funções moleculares e participar em interações múltiplas com outras proteínas, organelas ou localizações celulares. A estrutura do GO é representada com um gráfico acíclico direto conhecido como DAG (directed acyclic graph), onde as relações são diretas, como por exemplo, a mitocôndria é uma organela, mas uma organela não é uma mitocôndria. A organização deste gráfico consiste em termos child (filhos), que são mais especializados e parents (pais), que são menos específicos, no entanto, cada termo pode possuir mais de um termo parent, e também termos sibling (irmãos) (Martin et al., 2004). Os termos são ligados por relações do tipo is a (é um) e part of (é parte de) conforme exemplificado na Figura 6. 


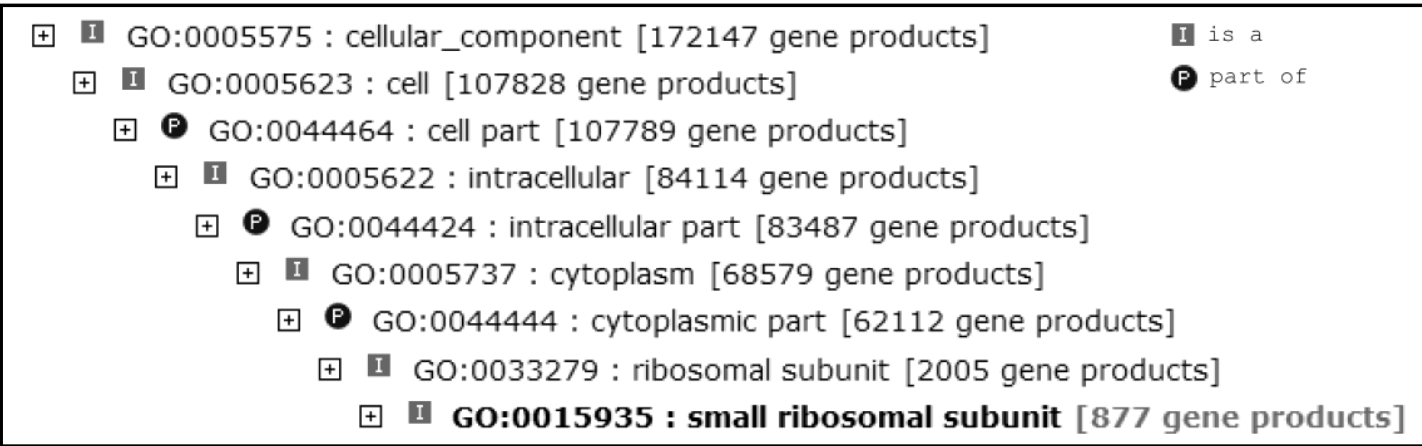

Figura 6 - Exemplo de gráfico acíclico direto (DAG) de termos GO, mostrando a estrutura hierárquica e as relações entre os termos: is a (é um) e part of (é parte de).

O COG (Clusters of Orthologous Groups of proteins) (Tatusov et al., 2000) é uma das bases de dados de ortológos mais antigas sendo composta atualmente por 66 organismos unicelulares e a base de dados equivalente para eucariotos é denominada de KOG (euKaryotic Orthologous Groups). Apesar de não serem atualizadas desde 2003, são consideradas por muitos autores como a base de dados de ortólogos padrão (Altenhoff e Dessimoz, 2009). A base de dados de KOG inclui proteínas de 7 genomas de eucariotos: três de animais (Caenorhabditis elegans, Drosophila melanogaster e Homo sapiens), uma planta Arabidopsis thaliana, dois fungos (Saccharomyces cerevisiae e Schizosaccharomyces pombe) e o parasita intracelular microsporídeo Encephalitozoon cuniculi, que atualmente pertencente ao Reino Fungi. O conjunto atual de KOG consiste de 4.852 clusters de ortólogos, que incluem 59.838 proteínas (Tatusov et al., 2003).

Cada KOG consiste de um gene ortólogo individual ou de grupos de ortólogos parálogos de 3 ou mais linhagens filogenéticas (cada genoma é considerado uma linhagem filogenética). Em outras palavras, quaisquer duas proteínas provenientes de diferentes linhagens, e que pertençam ao mesmo KOG são consideradas ortólogas. Assume-se que cada $\mathrm{COG} / \mathrm{KOG}$ evoluiu de um ancestral comum através de uma série de eventos de especiação e duplicação. Para definição dos KOGs, as seqüências codificadoras de proteínas dos sete genomas eucarióticos foram comparadas entre si, e para cada proteína, o melhor hit (best hit - BeT), ou seja, o melhor alinhamento encontrado contra cada um dos outros genomas foi computado. 
Se um dos genomas possui BeTs em outros dois genomas, considera-se que estas seqüências sejam ortólogas, e, portanto, este é o critério utilizado para definir uma unidade mínima de KOG (Tatusov et al., 1997).

\subsection{Estudo da expressão gênica em Eimeria spp.}

\subsubsection{Transcriptoma}

Vários projetos para geração de ESTs de Eimeria de galinha doméstica, envolvendo diferentes estágios do ciclo de vida destes parasitas foram realizados. Até o momento foram depositadas no GenBank cerca de 35.000 sequências ESTs (Expressed Sequence Tags) de E. tenella, das quais $80 \%$ destas foram obtidas a partir de estágios esporozoítos e merozoítos de segunda geração. Grande parte destas seqüências depositadas foram resultantes do projeto WashU-Merck E. tenella estabelecido entre a Washington University e a Merck, que produziu 27,500 ESTs. Cerca de 1.000 seqüências foram produzidas pela University Kebangsann Malaysia ( $\mathrm{Ng}$ et al., 2002; Wan et al., 1999), 499 ESTs foram gerados a partir de oocistos esporulados e não esporulados pelo USDA (United States Departamento of Agriculture) (Miska et al., 2004). Welcome Trust Sanger Institute gerou mais de 8.000 ESTs incluindo oocistos não esporulados, esporozoítos e merozoítos de primeira geração (dados não publicados), destas aproximadamente 2.500 seqüências já estão disponíveis publicamente no Genbank.

Além destas ESTs convencionais, o nosso grupo, como parte integrante do

Consórcio Internacional do Genoma de E. tenella (http://www.sanger.ac.uk/Projects/E tenella/consortium.shtml) foi responsável pelo sequenciamento de mais de 15.000 ESTs do tipo ORESTES (Open Reading Frame EST) para cada uma das três principais espécies de Eimeria de galinha doméstica: E. acervulina, E. maxima e E. tenella (Shirley et al., 2004b). Em E. tenella, as seqüências geradas pelo nosso grupo, foram obtidas a partir de diferentes estágios 
evolutivos deste parasita, incluindo: oocistos esporulados, oocistos parcialmente esporulados, oocistos não esporulados, merozoítos de $2^{a}$ geração e esporozoítos.

Protocolos de anotação automática de sequências ORESTES de Eimeria spp. de galinha doméstica foram desenvolvidos pela nossa equipe de bioinformática e aplicados aos conjuntos de dados utilizando-se componentes recém-desenvolvidos para a plataforma EGene (Durham et al., 2005; Ferro, 2008). No caso de E. tenella, além dos dados de ORESTES, foram utilizados os ESTs convencionais disponíveis publicamente, o que permitiu uma cobertura tanto das regiões centrais dos transcritos, obtidas pelos ORESTES, quanto das regiões terminais. Para E. maxima e E. acervulina, foram usadas somente as sequências ORESTES produzidas pelo nosso grupo.

Os dados relativos à anotação automática estão disponíveis no sítio www.coccidia.icb.usp.br/eimeria/annotation/. O sítio web encontra-se provisoriamente protegido por senha (username consortium, senha etgc2005). Esta página web disponibiliza atualmente os produtos da anotação para estas três espécies de Eimeria, a montagem das seqüências, a classificação dos termos de ontologia gênica (GO), anotação na base de dados KOG, além de uma base de dados relacional.

\subsubsection{Expressão gênica diferencial}

A Eimeria apresenta um ciclo de vida complexo, envolvendo vários estágios de desenvolvimento, e pouco se sabe quais são os conjuntos de genes mais importantes e expressos em cada um dos estágios de desenvolvimento da Eimeria. Por exemplo, as formas zoítas como esporozoítos, merozoítos de primeira geração e merozoítos de segunda geração apresentam uma morfologia relativamente semelhante, e compartilham funcionalmente a utilização do complexo apical para a adesão e penetração dos parasitas nas células do hospedeiro. As fases de proliferação são críticas para a patogênese no hospedeiro, enquanto o ciclo sexual é de suma importância para a transmissão, dispersão e geração da diversidade 
genética. Apesar dos oocistos não esporulados não serem infectantes, no ambiente sob condições adequadas, o processo de esporulação é disparado. Os oocistos de Eimeria responsáveis pela dispersão da doença para novos hospedeiros são capazes de permanecer no ambiente por longos períodos devido à proteção conferida pela parede dos oocistos (Belli et al., 2005; Schmatz, 1997).

Em Toxoplasma gondii e Plasmodium falciparum, a análise do perfil de transcrição em diferentes estágios evolutivos, revelou a predominância de grupos de genes diferencialmente expressos e predominantemente estágio-específicos (Bozdech et al., 2003; Cleary et al., 2002; Duncan, 2004; Llinas e DeRisi, 2004). Estudos dos níveis protéicos também indicaram um perfil de expressão semelhante (Hall et al., 2005; Xia et al., 2008).

Estudos comparativos entre diferentes estágios evolutivos de Eimeria já foram descritos, no entanto, grande parte destes utilizou um número de transcritos reduzido, ou a caracterização estágio-específica foi direcionada a um determinado gene ou a uma família de genes específicos.

Wan et al. (1999), analisando 500 ESTs provenientes de merozoítos de segunda geração, observou que $47,7 \%$ destas ESTs tiveram resultados positivos em buscas de similaridade empregando o programa BLAST, incluindo proteínas de ribossomo (correspondentes a quase um terço dos resultados positivos), um grupo de proteínas com funções enzimáticas, tais como quinases, oxidases, desidrogenases, sintetases, entre outras, e um grupo de ESTs com identidades putativas representando moléculas com uma vasta gama de funções. Dentro destes três grupos, 14,3\% representaram genes previamente identificados para E. tenella. Um estudo muito similar realizado pelo mesmo grupo ( $\mathrm{Ng}$ et al., 2002) analisou 556 ESTs provenientes de esporozoítos. Após a busca por similaridade por BLAST foi observado um padrão distinto ao observado em merozoítos. Apenas $27,3 \%$ das seqüências apresentaram resultados positivos, sendo que destes, 22,5\% representaram genes nunca estudados em E. tenella. ESTs com funções putativas foram classificadas em 10 grupos baseado em suas funções biológicas, para tanto, foram utilizadas 125 seqüências de esporozoítos e 179 seqüências de merozoítos. Esporozoítos mostraram um maior número de transcritos associados com crescimento celular, divisão celular e síntese de DNA, enquanto que merozoítos apresentaram transcritos envolvidos com a expressão de genes e proteínas. 
Uma análise de mais de 55.000 ESTs de organismos do Filo Apicomplexa incluindo cerca de 13.500 ESTs provenientes de Eimeria tenella foi realizada por $\mathrm{Li}$ et al. (2003). Quando comparadas, $80 \%$ das seqüências provenientes de esporozoítos e merozoítos de Eimeria tenella, foram classificadas como estágioespecíficos. e, interessantemente, o mesmo índice de transcritos estágio-específicos foi encontrado quando formas assexuais de Plasmodium falciparum foram analisadas.

Um conjunto de 499 ESTs, 225 clones específicos de oocistos esporulados e 274 de oocistos não esporulados foram obtidos empregando o método de hibridização subtrativa (Miska et al., 2004). A montagem destas seqüências gerou 162 contigs dos quais $64 \%$ não apresentam resultados em buscas por similaridade empregando o programa BLAST. Em seguida, os dados provenientes dos oocistos foram comparados com seqüências disponíveis de outros estágios de Eimeria, metade dos transcritos únicos de oocistos esporulados foi também encontrada em merozoítos e esporozoítos, enquanto que $79 \%$ dos transcritos isolados de oocistos não esporulados não foram detectados em outros estágios de desenvolvimento. Não é surpresa que oocistos esporulados compartilhem semelhanças aos estágios invasivos, já que cada oocisto esporulado contém 8 esporozoítos no seu interior, entretanto, a outra metade dos transcritos não foi identificada e, segundo os autores, poderiam fazer parte de um grupo de genes com expressão limitada a oocistos esporulados (Miska et al., 2004).

Avaliando-se a presença de proteínas de micronema durante o processo de esporulação, Ryan et al. (2000) demonstraram que a expressão de genes destas proteínas é altamente coordenada. No início da esporulação muitas dessas proteínas foram detectadas em níveis baixos, mas, a partir de 22 horas, quando ocorre a maturação dos esporozoítos, cinco tipos de proteínas de micronema foram observadas em altos níveis. Entretanto, os RNAs mensageiros que codificam para estas proteínas foram detectados cerca de 10 a 12 horas antes, indicando um controle tanto transcricional, quanto pós-transcricional. Tomley et al., (2001) ao estudar e caracterizar a EtMIC4 (E. tenella Proteína de Micronema 4) verificaram que esta proteína também apresenta localização diferencial durante a esquizogonia. No início desta fase, esta proteína estava presente na extremidade apical dos esporozoítos, desaparecendo durante o progresso desse processo. Na etapa final, 
foi detectada novamente sendo observada tanto no citoplasma, quanto na periferia do esquizonte. Nos esquizontes totalmente maduros, a EtMIC4 foi localizada apenas na extremidade apical dos merozoítos.

A regulação da expressão gênica nos diferentes estágios de desenvolvimento de Eimeria tenella também foi relatada para outros genes. A EtCRK2, uma quinase dependente de ciclina, é transcrita tanto nas fases sexuais quanto assexuais do parasita, sendo diferencialmente expressa durante o processo de esporulação. Segundo Kinnaird et al. (2004) o nível do RNAm que codifica para esta proteína mostrou-se reduzido entre 6 a 12 horas de esporulação, e no final do processo, entre 40-48 horas, elevou-se novamente. Schaap et al. (2005) estudaram transcritos que codificam proteínas de ribossomo. Foi observado que estes transcritos são expressos de forma diferencial, representando cerca de $10 \%$ dos transcritos totais encontrados em merozoítos e praticamente não sendo detectados em oocistos e esporozoítos. Transcritos que codificam as proteínas de ribossomo L5 e L23 foram detectados nos esquizontes não sendo observados em oocistos esporulados.

Portanto, assim como já relatado para outros organismos do Filo Apicomplexa, a regulação da expressão gênica em Eimeria spp também parece ser estágio-específica. Considerando a importância da espécie Eimeria tenella tanto economicamente quanto como modelo de estudo para coccidiose, um aprofundamento do conhecimento da expressão de genes diferencialmente expressos nos estágios de desenvolvimento deste parasita pode ser de grande importância para a caracterização de genes fundamentais para que o ciclo biológico deste parasita se complete.

As fases invasivas têm um papel fundamental na patogênese da doença, os esporozoítos são os responsáveis pelo início da replicação endógena do parasita e são o maior alvo da resposta imune protetiva do hospedeiro (Lillehoj e Lillehoj, 2000), enquanto que os merozoítos de segunda geração estão relacionados à patogenia da doença propriamente dita ( $\mathrm{Ng}$ et al., 2002), sendo responsáveis pelos maiores danos causados à mucosa e submucosa intestinais (Schmatz, 1997).

Estudos comparativos realizados pelo nosso grupo a partir de seqüências ORESTES provenientes de diversos estágios de desenvolvimento do ciclo de Eimeria tenella sugerem que um pequeno conjunto de genes é altamente expresso em cada fase do ciclo de vida, e que menos de $20 \%$ dos genes são compartilhados 
entre os estágios estudados (Novaes et al., 2005). Estes dados foram obtidos a partir de bibliotecas normalizadas e, portanto, não refletem um quadro quantitativo, além disso, as ESTs convencionais disponíveis publicamente (em sua grande parte provenientes de esporozoítos e merozoítos) também não refletem completamente um perfil quantitativo, devido às limitações inerentes à técnica.

Assim, com o objetivo de se obter um perfil de expressão gênica em larga escala, tanto quantitativo quanto qualitativo, decidimos empregar a técnica de LongSAGE (Saha et al., 2002) para construção de bibliotecas a partir esporozoítos e merozoítos de segunda geração de E. tenella, duas fases invasivas de grande importância no ciclo de vida destes organismos.

Os dados gerados poderão fornecer novas informações em relação aos genes expressos nestes organismos, incluindo dados quantitativos mais acurados. Além disso, estes dados poderão complementar as informações atualmente disponíveis (ORESTES e ESTs), possibilitando um melhor conhecimento do transcriptoma destes parasitas e a elucidação de vários mecanismos moleculares ainda desconhecidos, como também os envolvidos na regulação das principais etapas do ciclo de vida destes parasitas.

O estudo de genes diferencialmente expressos entre estas duas fases não somente poderá contribuir para um melhor entendimento do processo de adesão e interiorização do parasita nas células do hospedeiro, como também no futuro poderão ser utilizados como alvos terapêuticos, permitindo assim o desenvolvimento de novas estratégias de controle da doença. 
6 CONCLUSÕES 


\section{CONCLUSÕES}

$\checkmark$ Foram construídas com sucesso bibliotecas de LongSAGE a partir dos estágios invasivos de merozoítos de segunda geração e esporozoítos de $E$. tenella, o que resultou em mais de 35.000 tags, das quais 9.516 são únicas;

$\checkmark$ Para extração, contagem e análise estatística das tags um pacote de programas intitulado SAGE Analysis foi desenvolvido pela nossa equipe de bioinformática;

$\checkmark$ Menos de $1 \%$ das tags encontradas é de alta expressão (>50x), o que significa que um pequeno conjunto de genes é altamente expresso em cada fase do parasita;

$\checkmark$ Aproximadamente $60 \%$ das tags foram mapeadas no genoma E. tenella, das quais $95 \%$ foram localizadas em apenas um sítio, o que sugere um mapeamento inequívoco da maior parte das tags;

$\checkmark$ A técnica de LongSAGE permitiu a identificação de transcritos alternativos, como os provenientes de poliadenilação heterogênea, splicing alternativo, transcritos antisense, além de tags mitocondriais;

$\checkmark$ Após análise estatística foram identificados 270 tags diferencialmente expressas entre estes estágios invasivos, das quais 199 foram mapeadas e reconstruídas a partir dos dados do transcriptoma de $E$. tenella (ESTs/ORESTES), destas, 197 foram anotadas;

$\checkmark$ Menos da metade dos transcritos anotados apresentou resultados positivos de BLAST, o que pode indicar que um grande número de genes de $E$. tenella ainda está por ser caracterizado, principalmente para esporozoítos;

$\checkmark$ O protocolo de anotação automática gerou dados consistentes, $87,4 \%$ dos transcritos com resultados de BLAST positivos apresentaram similaridade com seqüências de organismos do Filo Apicomplexa, e poucas alterações foram efetuadas após a curagem manual; 
$\checkmark$ Foi observado um perfil semelhante entre os dados de anotação, GO e KOG, onde um número maior de produtos protéicos provenientes de merozoítos apresentou resultados positivos relacionados à tradução, manutenção e dobramento de proteínas, resposta à estresse, transdução de sinal e invasão. Em esporozoítos, os poucos resultados encontrados estão relacionados ao metabolismo de aminoácidos, transporte e atividade catalítica;

$\checkmark$ O pequeno conjunto de genes submetidos a experimentos de RT-qPCR apresentou uma boa correlação com os dados obtidos por LongSAGE, tanto com relação à expressão estágio-específica, quanto aos dados quantitativos.

$\checkmark$ A comparação dos dados de LongSAGE com os de Northern Digital de ESTS/ORESTES de E. tenella sugere que há uma boa correlação entre os dados diferencialmente expressos, tanto na anotação quanto na expressão estágio específica; 


\section{REFERÊNCIAS BIBLIOGRÁFICAS}

Adams MD, Kelley JM, Cocaine JD, Dubnick M, Polymeropoulos MH, Xiao H, et al. Complementary DNA sequencing: expressed sequence tags and human genome project. Science. 1991 Jun $21 ; 252(5013): 1651-6$.

Akmaev VR, Wang CJ. Correction of sequence-based artifacts in serial analysis of gene expression. Bioinformatics. 2004 May 22;20(8):1254-63.

Alba R, Fei Z, Payton P, Liu Y, Moore SL, Debbie P, Cohn J, D'Ascenzo M, Gordon JS, Rose JK, Martin G, Tanksley SD, Bouzayen M, Jahn MM, Giovannoni J. ESTs, cDNA microarrays, and gene expression profiling: tools for dissecting plant physiology and development. Plant J. 2004 Sep;39(5):697-714.

Allen PC, Fetterer RH. Recent advances in biology and immunobiology of Eimeria species and in diagnosis and control of infection with these coccidian parasites of poultry. Clin Microbiol Rev. 2002 Jan;15(1):58-65.

Altenhoff AM, Dessimoz C. Phylogenetic and functional assessment of orthologs inference projects and methods. PLoS Comput Biol. 2009 Jan;5(1):e1000262.

Ashburner M, Ball CA, Blake JA, Botstein D, Butler H, Cherry JM, Davis AP, Dolinski K, Dwight SS, Eppig JT, Harris MA, Hill DP, Issel-Tarver L, Kasarskis A, Lewis S, Matese JC, Richardson JE, Ringwald M, Rubin GM, Sherlock G. Gene ontology: tool for the unification of biology. The Gene Ontology Consortium. Nat Genet. 2000 May;25(1):25-9.

Avison MB. Differential display, subtractive hybridization,amplification suppression and SAGE techniques for measuring gene expression. In: Avison MB, editor. Measuring Gene Expression. New York (USA): Taylor \& Francis Group; 2008. p. 217-44.

Ball SJ, Pittilo RM, Long PL. Intestinal and extraintestinal life cycles of eimeriid coccidia. Adv Parasitol. 1989;28:1-54.

Bell AS, Ranford-Cartwright LC. Real-time quantitative PCR in parasitology. Trends Parasitol. 2002 Aug;18(8):337-42.

Belli SI, Walker RA, Flowers SA. Global protein expression analysis in apicomplexan parasites: current status. Proteomics. 2005 Mar;5(4):918-24.

Bianchetti L, Wu Y, Guerin E, Plewniak F, Poch O. SAGETTARIUS: a program to reduce the number of tags mapped to multiple transcripts and to plan SAGE sequencing stages. Nucleic Acids Res. 2007;35(18):e122. 
Blake DP, Qin Z, Cai J, Smith AL. Development and validation of real-time polymerase chain reaction assays specific to four species of Eimeria. Avian Pathol. 2008 Feb;37(1):89-94.

Bozdech Z, Zhu J, Joachimiak MP, Cohen FE, Pulliam B, DeRisi JL. Expression profiling of the schizont and trophozoite stages of Plasmodium falciparum with a long-oligonucleotide microarray. Genome Biol. 2003;4(2):R9.

Brenner S, Johnson M, Bridgham J, Golda G, Lloyd DH, Johnson D, Luo S, McCurdy S, Foy M, Ewan M, Roth R, George D, Eletr S, Albrecht G, Vermaas E, Williams SR, Moon K, Burcham T, Pallas M, DuBridge RB, Kirchner J, Fearon K, Mao J, Corcoran K. Gene expression analysis by massively parallel signature sequencing (MPSS) on microbead arrays. Nat Biotechnol. 2000 Jun;18(6):630-4.

Bromley E, Leeds N, Clark J, McGregor E, Ward M, Dunn MJ, Tomley F. Defining the protein repertoire of microneme secretory organelles in the apicomplexan parasite Eimeria tenella. Proteomics. 2003 Aug;3(8):1553-61.

Bumstead J, Tomley F. Induction of secretion and surface capping of microneme proteins in Eimeria tenella. Mol Biochem Parasitol. 2000 Oct;110(2):311-21.

Cai X, Fuller AL, McDougald LR, Zhu G. Apicoplast genome of the coccidian Eimeria tenella. Gene. 2003 Dec 4;321:39-46.

Chapman HD, Shirley MW. The Houghton strain of Eimeria tenella: a review of the type strain selected for genome sequencing. Avian Pathol. 2003 Apr;32(2):115-27.

Chapman HD, Cherry TE, Danforth HD, Richards G, Shirley MW, Williams RB. Sustainable coccidiosis control in poultry production: the role of live vaccines. Int $\mathrm{J}$ Parasitol. 2002 May;32(5):617-29.

Chen J, Sun M, Lee S, Zhou G, Rowley JD, Wang SM. Identifying novel transcripts and novel genes in the human genome by using novel SAGE tags. Proc Natl Acad Sci U S A. 2002 Sep 17;99(19):12257-62.

Clark JD, Billington K, Bumstead JM, Oakes RD, Soon PE, Sopp P, Tomley FM, Blake DP. A toolbox facilitating stable transfection of Eimeria species. Mol Biochem Parasitol. 2008 Nov;162(1):77-86.

Cleary MD, Singh U, Blader IJ, Brewer JL, Boothroyd JC. Toxoplasma gondii asexual development: identification of developmentally regulated genes and distinct patterns of gene expression. Eukaryot Cell. 2002 Jun;1(3):329-40.

Current WL, Upton SJ, Long PL. Taxonomy and Life Cycles. In: Long PL, editor. Coccidiosis of Man and Domestical Animals. Boston: CRC Press Inc; 1990. p. 1-17.

Dalloul RA, Lillehoj HS. Recent advances in immunomodulation and vaccination strategies against coccidiosis. Avian Dis. 2005 Mar;49(1):1-8. 
de Venevelles P, Chich JF, Faigle W, Loew D, Labbe M, Girard-Misguich F, Pery P. Towards a reference map of Eimeria tenella sporozoite proteins by two-dimensional electrophoresis and mass spectrometry. Int J Parasitol. 2004 Nov;34(12):1321-31.

Dias Neto E, Correa RG, Verjovski-Almeida S, Briones MR, Nagai MA, da Silva W, Jr., Zago MA, Bordin S, Costa FF, Goldman GH, Carvalho AF, Matsukuma A, Baia GS, Simpson DH, Brunstein A, de Oliveira PS, Bucher P, Jongeneel CV, O'Hare MJ, Soares F, Brentani RR, Reis LF, de Souza SJ, Simpson AJ. Shotgun sequencing of the human transcriptome with ORF expressed sequence tags. Proc Natl Acad Sci U S A. 2000 Mar 28;97(7):3491-6.

Diatchenko L, Lau YF, Campbell AP, Chenchik A, Moqadam F, Huang B, Lukyanov S, Lukyanov K, Gurskaya N, Sverdlov ED, Siebert PD. Suppression subtractive hybridization: a method for generating differentially regulated or tissue-specific cDNA probes and libraries. Proc Natl Acad Sci U S A. 1996 Jun 11;93(12):6025-30.

Dimmer EC, Huntley RP, Barrell DG, Binns D, Draghici S, Camon EB, Hubank M, Talmud PJ, Apweiler R, Lovering RC. The Gene Ontology - Providing a Functional Role in Proteomic Studies. Proteomics. 2008 Jul 17.

Dinel S, Bolduc C, Belleau P, Boivin A, Yoshioka M, Calvo E, Piedboeuf B, Snyder $\mathrm{EE}$, Labrie F, St-Amand J. Reproducibility, bioinformatic analysis and power of the SAGE method to evaluate changes in transcriptome. Nucleic Acids Res. 2005;33(3):e26.

Dubremetz JF, Garcia-Reguet N, Conseil V, Fourmaux MN. Apical organelles and host-cell invasion by Apicomplexa. Int J Parasitol. 1998 Jul;28(7):1007-13.

Dufva M. Introduction to Microarray Technology. In: Dufva M, editor. DNA Microarrays for Biomedical Research. New York (USA): Humana Press; 2009. p. 122.

Duncan R. DNA microarray analysis of protozoan parasite gene expression: outcomes correlate with mechanisms of regulation. Trends Parasitol. 2004 May;20(5):211-5.

Durham AM, Kashiwabara AY, Matsunaga FT, Ahagon PH, Rainone F, Varuzza L, Gruber A. EGene: a configurable pipeline generation system for automated sequence analysis. Bioinformatics. 2005 Jun 15;21(12):2812-3.

Entzeroth R, Mattig FR, Werner-Meier R. Structure and function of the parasitophorous vacuole in Eimeria species. Int J Parasitol. 1998 Jul;28(7):1015-8.

Fernandez S, Pagotto AH, Furtado MM, Katsuyama AM, Madeira AM, Gruber A. A multiplex PCR assay for the simultaneous detection and discrimination of the seven Eimeria species that infect domestic fowl. Parasitology. 2003 Oct;127(Pt 4):317-25. 
Fernando MA. Eimeria: Infections of the Intestine. In: Long PL, editor. Coccidiosis of Man and Domestical Animals. Boston: CRC Press Inc; 1990. p. 63-75.

Ferro M. Desenvolvimento e validação de protocolos para a anotação automática de seqüências ORESTES de Eimeria spp. de galinha doméstica [Dissertação (Mestrado em Ciências - Biologia da Relação Patógeno Hospedeiro)]. São Paulo: Instituto de Ciências Biomédicas da Universidade de São Paulo; 2008.

Fizames C, Munos S, Cazettes C, Nacry P, Boucherez J, Gaymard F, Piquemal D, Delorme V, Commes T, Doumas P, Cooke R, Marti J, Sentenac H, Gojon A. The Arabidopsis root transcriptome by serial analysis of gene expression. Gene identification using the genome sequence. Plant Physiol. 2004 Jan;134(1):67-80.

Green CD, Simons JF, Taillon BE, Lewin DA. Open systems: panoramic views of gene expression. J Immunol Methods. 2001 Apr;250(1-2):67-79.

Gruber A. Expressed sequence tags. In: Dear $\mathrm{PH}$, editor. Bioinformatics. Bloxham Mill, Oxfordshire (UK): Scion Publishing Limited; 2007. p. 141-67.

Guerfali FZ, Laouini D, Guizani-Tabbane L, Ottones F, Ben-Aissa K, Benkahla A, Manchon L, Piquemal D, Smandi S, Mghirbi O, Commes T, Marti J, Dellagi K. Simultaneous gene expression profiling in human macrophages infected with Leishmania major parasites using SAGE. BMC Genomics. 2008;9:238.

Hall N, Karras M, Raine JD, Carlton JM, Kooij TW, Berriman M, Florens L, Janssen CS, Pain A, Christophides GK, James K, Rutherford K, Harris B, Harris D, Churcher C, Quail MA, Ormond D, Doggett J, Trueman HE, Mendoza J, Bidwell SL, Rajandream MA, Carucci DJ, Yates JR, 3rd, Kafatos FC, Janse CJ, Barrell B, Turner $\mathrm{CM}$, Waters AP, Sinden RE. A comprehensive survey of the Plasmodium life cycle by genomic, transcriptomic, and proteomic analyses. Science. 2005 Jan 7;307(5706):82-6.

Hammod DM. Life Cycles and Development of Coccidia. In: Hammod DM, Long PL, editors. The Coccidia. Baltimore: University Park Press e London- Butterworths; 1973. p. $45-80$.

Harbers M, Carninci P. Tag-based approaches for transcriptome research and genome annotation. Nat Methods. 2005 Jul;2(7):495-502.

Heid CA, Stevens J, Livak KJ, Williams PM. Real time quantitative PCR. Genome Res. 1996 Oct;6(10):986-94.

Hene L, Sreenu VB, Vuong MT, Abidi SH, Sutton JK, Rowland-Jones SL, Davis SJ, Evans EJ. Deep analysis of cellular transcriptomes - LongSAGE versus classic MPSS. BMC Genomics. 2007;8:333.

Hu K, Johnson J, Florens L, Fraunholz M, Suravajjala S, DiLullo C, Yates J, Roos DS, Murray JM. Cytoskeletal components of an invasion machine--the apical complex of Toxoplasma gondii. PLoS Pathog. 2006 Feb;2(2):e13. 
Jaluria $\mathrm{P}$, Konstantopoulos $\mathrm{K}$, Betenbaugh $\mathrm{M}$, Shiloach J. A perspective on microarrays: current applications, pitfalls, and potential uses. Microb Cell Fact. 2007;6:4.

Johnston DA, Fernando MA. Eimeria spp. of the domestic fowl: analysis of genetic variability between species and strains using DNA polymorphisms amplified by arbitrary primers and denaturing gradient-gel electrophoresis. Parasitol Res. 1995;81(2):91-7.

Jones SJ, Riddle DL, Pouzyrev AT, Velculescu VE, Hillier L, Eddy SR, Stricklin SL, Baillie DL, Waterston R, Marra MA. Changes in gene expression associated with developmental arrest and longevity in Caenorhabditis elegans. Genome Res. 2001 Aug;11(8):1346-52.

Kawahara F, Taira K, Nagai S, Onaga H, Onuma M, Nunoya T. Detection of five avian Eimeria species by species-specific real-time polymerase chain reaction assay. Avian Dis. 2008 Dec;52(4):652-6.

Keime C, Semon M, Mouchiroud D, Duret L, Gandrillon O. Unexpected observations after mapping LongSAGE tags to the human genome. BMC Bioinformatics. 2007;8:154.

Khattra J, Delaney AD, Zhao Y, Siddiqui A, Asano J, McDonald H, Pandoh P, Dhalla N, Prabhu AL, Ma K, Lee S, Ally A, Tam A, Sa D, Rogers S, Charest D, Stott J, Zuyderduyn S, Varhol R, Eaves C, Jones S, Holt R, Hirst M, Hoodless PA, Marra MA. Large-scale production of SAGE libraries from microdissected tissues, flow-sorted cells, and cell lines. Genome Res. 2007 Jan;17(1):108-16.

Kim YC, Jung YC, Xuan Z, Dong H, Zhang MQ, Wang SM. Pan-genome isolation of low abundance transcripts using SAGE tag. FEBS Lett. 2006 Dec 11;580(2829):6721-9.

Kinnaird JH, Bumstead JM, Mann DJ, Ryan R, Shirley MW, Shiels BR, Tomley FM. EtCRK2, a cyclin-dependent kinase gene expressed during the sexual and asexual phases of the Eimeria tenella life cycle. Int J Parasitol. 2004 May;34(6):683-92.

Kirschbaum-Slager N, Parmigiani RB, Camargo AA, de Souza SJ. Identification of human exons overexpressed in tumors through the use of genome and expressed sequence data. Physiol Genomics. 2005 May 11;21(3):423-32.

Knoll-Gellida A, Andre M, Gattegno T, Forgue J, Admon A, Babin PJ. Molecular phenotype of zebrafish ovarian follicle by serial analysis of gene expression and proteomic profiling, and comparison with the transcriptomes of other animals. BMC Genomics. 2006;7:46.

Kogut MH. Host Specificity of the Coccidia. In: Long PL, editor. Coccidiosis of Man and Domestical Animals. Boston: CRC Press Inc; 1990. p. 43-62.

Koonin EV. Orthologs, paralogs, and evolutionary genomics. Annu Rev Genet. 2005;39:309-38. 
Kozian DH, Kirschbaum BJ. Comparative gene-expression analysis. Trends Biotechnol. 1999 Feb;17(2):73-8.

Kubista M, Andrade JM, Bengtsson M, Forootan A, Jonak J, Lind K, Sindelka R, Sjoback R, Sjogreen B, Strombom L, Stahlberg A, Zoric N. The real-time polymerase chain reaction. Mol Aspects Med. 2006 Apr-Jun;27(2-3):95-125.

Kuo BY, Chen Y, Bohacec S, Johansson O, Wasserman WW, Simpson EM. SAGE2Splice: unmapped SAGE tags reveal novel splice junctions. PLoS Comput Biol. 2006 Apr;2(4):e34.

Levine ND. Introduction, History, and Taxonomy. In: Hammod DM, Long PL, editors. The Coccidia. Baltimore: University Park Press e London- Butterworths; 1973. p. 122.

Levine ND. Progress in taxonomy of the Apicomplexan protozoa. J Protozool. 1988 Nov;35(4):518-20.

Li L, Brunk BP, Kissinger JC, Pape D, Tang K, Cole RH, Martin J, Wylie T, Dante M, Fogarty SJ, Howe DK, Liberator P, Diaz C, Anderson J, White M, Jerome ME, Johnson EA, Radke JA, Stoeckert CJ, Jr., Waterston RH, Clifton SW, Roos DS, Sibley LD. Gene discovery in the apicomplexa as revealed by EST sequencing and assembly of a comparative gene database. Genome Res. 2003 Mar;13(3):443-54.

Li Q, Zhao Y, Ni B, Yao C, Zhou Y, Xu W, Wang Z, Qiao Z. Comparison of the expression profiles of promastigotes and axenic amastigotes in Leishmania donovani using serial analysis of gene expression. Parasitol Res. 2008 Sep;103(4):821-8.

Li YJ, Xu P, Qin X, Schmechel DE, Hulette CM, Haines JL, Pericak-Vance MA, Gilbert JR. A comparative analysis of the information content in long and short SAGE libraries. BMC Bioinformatics. 2006;7:504.

Liang P, Pardee AB. Differential display of eukaryotic messenger RNA by means of the polymerase chain reaction. Science. 1992 Aug 14;257(5072):967-71.

Lillehoj HS, Lillehoj EP. Avian coccidiosis. A review of acquired intestinal immunity and vaccination strategies. Avian Dis. 2000 Apr-Jun;44(2):408-25.

Ling KH, Rajandream MA, Rivailler P, Ivens A, Yap SJ, Madeira AM, Mungall K, Billington K, Yee WY, Bankier AT, Carroll F, Durham AM, Peters N, Loo SS, Isa MN, Novaes J, Quail M, Rosli R, Nor Shamsudin M, Sobreira TJ, Tivey AR, Wai SF, White S, Wu X, Kerhornou A, Blake D, Mohamed R, Shirley M, Gruber A, Berriman M, Tomley F, Dear PH, Wan KL. Sequencing and analysis of chromosome 1 of Eimeria tenella reveals a unique segmental organization. Genome Res. 2007 Mar;17(3):3119.

Llinas M, DeRisi JL. Pernicious plans revealed: Plasmodium falciparum genome wide expression analysis. Curr Opin Microbiol. 2004 Aug;7(4):382-7. 
Long PL, Joyner LP. Problems in the identification of species of Eimeria. J Protozool. 1984 Nov;31(4):535-41.

Long PL, Millard BJ, Joyner LP, Norton CC. A guide to laboratory techniques used in the study and diagnosis of avian coccidiosis. Folia Vet Lat. 1976 Jul-Sep;6(3):201-17.

Lu J, Lal A, Merriman B, Nelson S, Riggins G. A comparison of gene expression profiles produced by SAGE, long SAGE, and oligonucleotide chips. Genomics. 2004 Oct;84(4):631-6.

MacPherson JM, Gajadhar AA. Differentiation of seven Eimeria species by random amplified polymorphic DNA. Vet Parasitol. 1993 Jan;45(3-4):257-66.

Margulies EH, Kardia SL, Innis JW. Identification and prevention of a GC content bias in SAGE libraries. Nucleic Acids Res. 2001 Jun 15;29(12):E60-0.

Martin DM, Berriman M, Barton GJ. GOtcha: a new method for prediction of protein function assessed by the annotation of seven genomes. BMC Bioinformatics. 2004 Nov 18;5:178.

Min W, Dalloul RA, Lillehoj HS. Application of biotechnological tools for coccidia vaccine development. J Vet Sci. 2004 Dec;5(4):279-88.

Miska KB, Fetterer RH, Barfield RC. Analysis of transcripts expressed by Eimeria tenella oocysts using subtractive hybridization methods. J Parasitol. 2004 Dec;90(6):1245-52.

Moody DE. Genomics Techniques: An overview of methods for the study of gene expression. J Anim Sci. 2001;79:E128-E35.

Morgan JA, Morris GM, Wlodek BM, Byrnes R, Jenner M, Constantinoiu CC, Anderson GR, Lew-Tabor AE, Molloy JB, Gasser RB, Jorgensen WK. Real-time polymerase chain reaction (PCR) assays for the specific detection and quantification of seven Eimeria species that cause coccidiosis in chickens. Mol Cell Probes. 2009 Apr;23(2):83-9.

Morrissette NS, Sibley LD. Cytoskeleton of apicomplexan parasites. Microbiol Mol Biol Rev. 2002 Mar;66(1):21-38; table of contents.

Munasinghe A, Patankar S, Cook BP, Madden SL, Martin RK, Kyle DE, Shoaibi A, Cummings LM, Wirth DF. Serial analysis of gene expression (SAGE) in Plasmodium falciparum: application of the technique to A-T rich genomes. Mol Biochem Parasitol. 2001 Mar;113(1):23-34.

Nagaraj SH, Gasser RB, Ranganathan S. A hitchhiker's guide to expressed sequence tag (EST) analysis. Brief Bioinform. 2007 Jan;8(1):6-21.

Ng ST, Sanusi Jangi M, Shirley MW, Tomley FM, Wan KL. Comparative EST analyses provide insights into gene expression in two asexual developmental stages of Eimeria tenella. Exp Parasitol. 2002 Jun-Jul;101(2-3):168-73. 
Novaes J, Kashiwabara AY, Varuzza L, Nagao LT, Manha APS, Fernandez S, Durham AM, Gruber A, Madeira AMBN. Survey of Eimeria spp. transcripts using open reading frame ESTs (ORESTES). In: The IX $\mathrm{X}^{\text {th }}$ International Coccidiosis Conference; 2005; Foz do Iguassu, Parana, Brazil. 2005. p. 150.

Ojopi EP, Oliveira PS, Nunes DN, Paquola A, DeMarco R, Gregorio SP, Aires KA, Menck CF, Leite LC, Verjovski-Almeida S, Dias-Neto E. A quantitative view of the transcriptome of Schistosoma mansoni adult-worms using SAGE. BMC Genomics. 2007;8:186.

Palm D, Weiland M, McArthur AG, Winiecka-Krusnell J, Cipriano MJ, Birkeland SR, Pacocha SE, Davids B, Gillin F, Linder E, Svard S. Developmental changes in the adhesive disk during Giardia differentiation. Mol Biochem Parasitol. 2005 Jun;141(2):199-207.

Patankar S, Munasinghe A, Shoaibi A, Cummings LM, Wirth DF. Serial analysis of gene expression in Plasmodium falciparum reveals the global expression profile of erythrocytic stages and the presence of anti-sense transcripts in the malarial parasite. Mol Biol Cell. 2001 Oct;12(10):3114-25.

Peirson SN, Butler JN, Foster RG. Experimental validation of novel and conventional approaches to quantitative real-time PCR data analysis. Nucleic Acids Res. $2003 \mathrm{Jul}$ 15;31(14):e73.

Ponchel F. Real-time PCR using SYBR $\circledast$ Green. In: Dorak MT, editor. Real-time PCR. New York (USA): Taylor \& Francis Group; 2006. p. 139-54.

Quére R, Manchon L, Lejeune M, Clément O, Pierrat F, Bonafoux B, Commes T, Piquemal D, Marti J. Mining SAGE data allows large-scale, sensitive screening of antisense transcript expression. Nucleic Acids Res. 2004;32(20):e163.

Radke JR, Behnke MS, Mackey AJ, Radke JB, Roos DS, White MW. The transcriptome of Toxoplasma gondii. BMC Biol. 2005;3:26.

Reinartz J, Bruyns E, Lin JZ, Burcham T, Brenner S, Bowen B, Kramer M, Woychik R. Massively parallel signature sequencing (MPSS) as a tool for in-depth quantitative gene expression profiling in all organisms. Brief Funct Genomic Proteomic. 2002 Feb;1(1):95-104.

Rivals E, Boureux A, Lejeune M, Ottones F, Perez OP, Tarhio J, Pierrat F, Ruffle F, Commes T, Marti J. Transcriptome annotation using tandem SAGE tags. Nucleic Acids Res. 2007;35(17):e108.

Robinson SJ, Parkin IA. Differential SAGE analysis in Arabidopsis uncovers increased transcriptome complexity in response to low temperature. BMC Genomics. 2008;9:434.

Romano CM. Caracterização molecular e análise comparativa de genomas mitocondriais de Eimeria spp. de galinha doméstica [Dissertação (Mestrado em 
Ciências - Biologia da Relação Patógeno-Hospedeiro)]. São Paulo: Instituto de Ciências Biomédicas da Universidade de São Paulo; 2004.

Roos DS. Genetics. Themes and variations in apicomplexan parasite biology. Science. 2005 Jul 1;309(5731):72-3.

Rosinski-Chupin I, Chertemps T, Boisson B, Perrot S, Bischoff E, Briolay J, Couble P, Menard R, Brey P, Baldacci P. Serial Analysis of Gene Expression in Plasmodium berghei salivary gland sporozoites. BMC Genomics. 2007;8:466.

Ryan R, Shirley M, Tomley F. Mapping and expression of microneme genes in Eimeria tenella. Int J Parasitol. 2000 Dec;30(14):1493-9.

Saha S, Sparks AB, Rago C, Akmaev V, Wang CJ, Vogelstein B, Kinzler KW, Velculescu VE. Using the transcriptome to annotate the genome. Nat Biotechnol. 2002 May;20(5):508-12.

Santos JM, Lebrun M, Daher W, Soldati D, Dubremetz JF. Apicomplexan cytoskeleton and motors: key regulators in morphogenesis, cell division, transport and motility. Int J Parasitol. 2009 Jan;39(2):153-62.

Schaap D, Arts G, van Poppel NF, Vermeulen AN. De novo ribosome biosynthesis is transcriptionally regulated in Eimeria tenella, dependent on its life cycle stage. Mol Biochem Parasitol. 2005 Feb;139(2):239-48.

Schena M, Shalon D, Davis RW, Brown PO. Quantitative monitoring of gene expression patterns with a complementary DNA microarray. Science. 1995 Oct 20;270(5235):467-70.

Schmatz DM. The mannitol cycle in Eimeria. Parasitology. 1997;114 Suppl:S81-9.

Schnitzler BE, Thebo PL, Mattsson JG, Tomley FM, Shirley MW. Development of a diagnostic PCR assay for the detection and discrimination of four pathogenic .Eimeria species of the chicken. Avian Pathol. 1998;27(5):490-7.

Schnitzler BE, Thebo PL, Tomley FM, Uggla A, Shirley MW. PCR identification of chicken Eimeria: a simplified read-out. Avian Pathol. 1999 Feb;28(1):89-93.

Shi T, Yan W, Ren H, Liu X, Suo X. Dynamic development of parasitophorous vacuole of Eimeria tenella transfected with the yellow fluorescent protein gene fused to different signal sequences from apicomplexan parasites. Parasitol Res. 2009 Jan;104(2):315-20.

Shirley MW. The genome of Eimeria spp., with special reference to Eimeria tenella--a coccidium from the chicken. Int J Parasitol. 2000 Apr 10;30(4):485-93.

Shirley MW, Bumstead N. Intra-specific variation within Eimeria tenella detected by the random amplification of polymorphic DNA. Parasitol Res. 1994;80(4):346-51. 
Shirley MW, Harvey DA. Eimeria tenella: genetic recombination of markers for precocious development and arprinocid resistance. Appl Parasitol. 1996 Dec;37(4):293-9.

Shirley MW, Harvey DA. A genetic linkage map of the apicomplexan protozoan parasite Eimeria tenella. Genome Res. 2000 Oct;10(10):1587-93.

Shirley MW, Smith AL, Tomley FM. The biology of avian Eimeria with an emphasis on their control by vaccination. Adv Parasitol. 2005;60:285-330.

Shirley MW, Smith AL, Blake DP. Challenges in the successful control of the avian coccidia. Vaccine. 2007 Jul 26;25(30):5540-7.

Shirley MW, Blake D, White SE, Sheriff R, Smith AL. Integrating genetics and genomics to identify new leads for the control of Eimeria spp. Parasitology. 2004a;128 Suppl 1:S33-42.

Shirley MW, Ivens A, Gruber A, Madeira AM, Wan KL, Dear PH, Tomley FM. The Eimeria genome projects: a sequence of events. Trends Parasitol. 2004b May;20(5):199-201.

Sibley LD. Intracellular parasite invasion strategies. Science. 2004 Apr 9;304(5668):248-53.

Siddiqui AS, Delaney AD, Schnerch A, Griffith OL, Jones SJ, Marra MA. Sequence biases in large scale gene expression profiling data. Nucleic Acids Res. 2006;34(12):e83.

Silva AP, De Souza JE, Galante PA, Riggins GJ, De Souza SJ, Camargo AA. The impact of SNPs on the interpretation of SAGE and MPSS experimental data. Nucleic Acids Res. 2004;32(20):6104-10.

Silveira NJ, Varuzza L, Machado-Lima A, Lauretto MS, Pinheiro DG, Rodrigues RV, Severino P, Nobrega FG, Silva WA Jr, de BPCA, Tajara EH. Searching for molecular markers in head and neck squamous cell carcinomas (HNSCC) by statistical and bioinformatic analysis of larynx-derived SAGE libraries. BMC Med Genomics. 2008;1:56.

Skuce PJ, Yaga R, Lainson FA, Knox DP. An evaluation of serial analysis of gene expression (SAGE) in the parasitic nematode, Haemonchus contortus. Parasitology. 2005 May;130(Pt 5):553-9.

Smith AL, Hesketh P, Archer A, Shirley MW. Antigenic diversity in Eimeria maxima and the influence of host genetics and immunization schedule on cross-protective immunity. Infect Immun. 2002 May;70(5):2472-9.

Sterky F, Lundeberg J. Sequence analysis of genes and genomes. J Biotechnol. 2000 Jan 7;76(1):1-31. 
Striepen B, White MW, Li C, Guerini MN, Malik SB, Logsdon JM, Jr., Liu C, Abrahamsen MS. Genetic complementation in apicomplexan parasites. Proc Natl Acad Sci U S A. 2002 Apr 30;99(9):6304-9.

Sun M, Zhou G, Lee S, Chen J, Shi RZ, Wang SM. SAGE is far more sensitive than EST for detecting low-abundance transcripts. BMC Genomics. 2004 Jan 5;5(1):1.

Taft AS, Vermeire JJ, Bernier J, Birkeland SR, Cipriano MJ, Papa AR, McArthur AG, Yoshino TP. Transcriptome analysis of Schistosoma mansoni larval development using serial analysis of gene expression (SAGE). Parasitology. 2009 Apr;136(5):46985.

Tatusov RL, Koonin EV, Lipman DJ. A genomic perspective on protein families. Science. 1997 Oct 24;278(5338):631-7.

Tatusov RL, Galperin MY, Natale DA, Koonin EV. The COG database: a tool for genome-scale analysis of protein functions and evolution. Nucleic Acids Res. 2000 Jan 1;28(1):33-6.

Tatusov RL, Fedorova ND, Jackson JD, Jacobs AR, Kiryutin B, Koonin EV, Krylov DM, Mazumder R, Mekhedov SL, Nikolskaya AN, Rao BS, Smirnov S, Sverdlov AV, Vasudevan S, Wolf YI, Yin JJ, Natale DA. The COG database: an updated version includes eukaryotes. BMC Bioinformatics. 2003 Sep 11;4:41.

Tenter AM, Barta JR, Beveridge I, Duszynski DW, Mehlhorn H, Morrison DA, Thompson RC, Conrad PA. The conceptual basis for a new classification of the coccidia. Int J Parasitol. 2002 May;32(5):595-616.

Tomley F. Apicomplexan biology in the post-genomic era: perspectives from the European COST Action 857. Int J Parasitol. 2009 Jan;39(2):133-4.

Tomley FM, Soldati DS. Mix and match modules: structure and function of microneme proteins in apicomplexan parasites. Trends Parasitol. 2001 Feb;17(2):818.

Tomley FM, Billington KJ, Bumstead JM, Clark JD, Monaghan P. EtMIC4: a microneme protein from Eimeria tenella that contains tandem arrays of epidermal growth factor-like repeats and thrombospondin type-I repeats. Int J Parasitol. 2001 Oct;31(12):1303-10.

Tuteja R, Tuteja N. Serial Analysis of Gene Expression: Applications in Human Studies. J Biomed Biotechnol. 2004;2004(2):113-20.

Tyzzer EE. Coccidiosis in gallinaceous birds. Am J Hyg. 1929(10):269-83.

Valasek MA, Repa JJ. The power of real-time PCR. Adv Physiol Educ. 2005 Sep;29(3):151-9.

van Ruissen F, Schaaf GJ, Kool M, Bass F, Ruijter JM. Scaling of Gene Expression Data Allowing the Comparison of Different Gene Expression Platforms. In: Nielsen 
KL, editor. Serial Analysis of Gene Expression (SAGE). Totowa, New Jersey (USA): Humana Press; 2008.

Varuzza L. Métodos Estatísticos para a análise de bibliotecas digitais de expressão gênica [Doutorado (Programa Interunidades de Bioinformática)]. São Paulo: Universidade de São Paulo; 2008.

Velculescu VE. Essay: Amersham Pharmacia Biotech \& Science prize. Tantalizing transcriptomes--SAGE and its use in global gene expression analysis. Science. 1999 Nov 19;286(5444):1491-2.

Velculescu VE, Vogelstein B, Kinzler KW. Analysing uncharted transcriptomes with SAGE. Trends Genet. 2000 Oct;16(10):423-5.

Velculescu VE, Zhang L, Vogelstein B, Kinzler KW. Serial analysis of gene expression. Science. 1995 Oct 20;270(5235):484-7.

Velculescu VE, Zhang L, Zhou W, Vogelstein J, Basrai MA, Bassett DE, Jr., Hieter P, Vogelstein B, Kinzler KW. Characterization of the yeast transcriptome. Cell. 1997 Jan 24;88(2):243-51.

Wahl MB, Heinzmann U, Imai K. LongSAGE analysis significantly improves genome annotation: identifications of novel genes and alternative transcripts in the mouse. Bioinformatics. 2005a Apr 15;21(8):1393-400.

Wahl MB, Heinzmann U, Imai K. LongSAGE analysis revealed the presence of a large number of novel antisense genes in the mouse genome. Bioinformatics. 2005b Apr 15;21(8):1389-92.

Wahl MB, Caldwell RB, Kierzek AM, Arakawa H, Eyras E, Hubner N, Jung C, Soeldenwagner M, Cervelli M, Wang YD, Liebscher V, Buerstedde JM. Evaluation of the chicken transcriptome by SAGE of B cells and the DT40 cell line. BMC Genomics. 2004 Dec 21;5(1):98.

Waller RF, McFadden Gl. The apicoplast: a review of the derived plastid of apicomplexan parasites. Curr Issues Mol Biol. 2005 Jan;7(1):57-79.

Wan KL, Chong SP, Ng ST, Shirley MW, Tomley FM, Jangi MS. A survey of genes in Eimeria tenella merozoites by EST sequencing. Int J Parasitol. 1999 Dec;29(12):1885-92.

Wang X, Zhao Y, Wong K, Ehlers P, Kohara Y, Jones SJ, Marra MA, Holt RA, Moerman DG, Hansen D. Identification of genes expressed in the hermaphrodite germ line of C. elegans using SAGE. BMC Genomics. 2009;10:213.

Welsh J, Chada K, Dalal SS, Cheng R, Ralph D, McClelland M. Arbitrarily primed PCR fingerprinting of RNA. Nucleic Acids Res. 1992 Oct 11;20(19):4965-70.

Williams DL, Sayed AA, Bernier J, Birkeland SR, Cipriano MJ, Papa AR, McArthur AG, Taft A, Vermeire JJ, Yoshino TP. Profiling Schistosoma mansoni development 
using serial analysis of gene expression (SAGE). Exp Parasitol. 2007 Nov;117(3):246-58.

Williams RB. Epidemiological aspects of the use of live anticoccidial vaccines for chickens. Int J Parasitol. 1998 Jul;28(7):1089-98.

Wu X. Workflow-based systematic design of high throughput genome annotation [Ph. D. Thesis]. London: Imperial College London Department of Computing; 2008.

Xia D, Sanderson SJ, Jones AR, Prieto JH, Yates JR, Bromley E, Tomley FM, Lal K, Sinden RE, Brunk BP, Roos DS, Wastling JM. The proteome of Toxoplasma gondii: integration with the genome provides novel insights into gene expression and annotation. Genome Biol. 2008;9(7):R116.

Yamamoto M, Wakatsuki T, Hada A, Ryo A. Use of serial analysis of gene expression (SAGE) technology. J Immunol Methods. 2001 Apr;250(1-2):45-66.

Yan W, Liu X, Shi T, Hao L, Tomley FM, Suo X. Stable transfection of Eimeria tenella: constitutive expression of the YFP-YFP molecule throughout the life cycle. Int J Parasitol. 2009 Jan;39(1):109-17.

Zou J, Liu X, Shi T, Huang X, Wang H, Hao L, Yin G, Suo X. Transfection of Eimeria and Toxoplasma using heterologous regulatory sequences. Int J Parasitol. 2009 Sep;39(11):1189-93. 